\title{
El tribunal de Bertoldo: Delegación constitucional en el diseño de instituciones judiciales
}

\author{
Bertoldo's Court: \\ Constitutional Delegation in the Design of Judicial Institutions
}

\author{
EugENio García-Huidobro* \\ SEBASTIÁN GUIDI* *
}

\begin{abstract}
Resumen
La Convención Constitucional chilena deberá diseñar una multiplicidad de novedosas y complejas instituciones, muchas de ellas de carácter judicial. Al hacerlo, este ensayo sugiere que respecto de estas últimas deberá procurar hacerlo con un alto grado de detalle para evitar que la implementación de estas instituciones judiciales no sea excesivamente retrasada ni manipulada por futuras mayorías parlamentarias. Para argumentar en este sentido, se recogen tres experiencias del derecho comparado. En la Constitución italiana de 1948, la vaguedad en la regulación de la Corte Constitucional llevó a demoras en su implementación cruzadas por intentos de captura por parte del partido gobernante. En la reforma constitucional argentina de 1994, la deficiente regulación del Consejo de la Magistratura permitió que casi todos los gobiernos hayan intentado o logrado reformar su composición para aumentar el control político sobre este. En la Constitución chilena de 1925, la raquítica regulación de los tribunales administrativos permitió, derechamente, que estos nunca fueran implementados.

Si bien los defectos en la regulación constitucional no son el único factor que explica el fracaso de estas instituciones, éstos dificultaron la coordinación entre sectores políticos y proveyeron de excusas a quienes no deseaban implementarlas.
\end{abstract}

Palabras clave: Derecho constitucional comparado; diseño constitucional; asambleas constituyentes; instituciones judiciales.

Abstract
The Chilean Constitutional Convention will have to design multiple novel and
complex institutions, many of them having a judicial character. Within this process,
this essay suggests that regarding these judicial institutions, the Convention should
endeavor to design them in a very detailed way, to avoid excessive delays or
manipulations from Parliamentarian majorities. In the Italian Constitution of 1948,
the vagueness on the regulation of the Constitutional Court led to delays in its
implementation, dominated by capture attempts from the governing party. In the

\footnotetext{
* Centro de Estudios Públicos, Chile (egarciahuidobro@cepchile.cl). ORCID: http://orcid.org/0000-0003-04700234. Artículo recibido el 17 de junio de 2021, aceptado para su publicación el 29 de julio de 2021.

** Universidad Torcuato di Tella, Argentina (sebastian.guidi@yale.edu). ORCID: http://orcid.org/0000-00027654-3787.
} 


\begin{abstract}
Argentinian constitutional reform of 1994, the deficient regulation of the Judiciary Council allowed that almost all governments attempted to or were able to change its composition to increase their political control over it. In the Chilean Constitution of 1925, the skimpy regulation of the administrative courts caused that, straightforwardly, they were never created.

Even though these defects in the constitutional regulation are not the only factor that explains the failure of these institutions, they nevertheless posed difficulties to the coordination among political participants, and they provided excuses to the ones who did not want to implement them.
\end{abstract}

Keywords: Comparative constitutional law; constitutional design; constitutional assemblies; judicial institutions.

\title{
INTRODUCCIÓN
}

Quienes redactan una constitución se encuentran con frecuencia en la situación del rey Alboino. Según cuenta el relato medieval italiano, harto de las travesuras de su pícaro consejero Bertoldo, el rey lo condena a muerte. Bertoldo logra sin embargo una última gracia: elegir un árbol de su agrado del que ser colgado. Confundido, el rey acepta y ordena a sus soldados colgarlo de ese árbol una vez que sea encontrado. Bertoldo se hace llevar por todos los bosques, valles y montañas de la península en su búsqueda, sin lograr dar con él. Aquí las versiones difieren: según algunos, la exhausta guardia real libera a Bertoldo al no poder cumplir con la orden del rey; según otros, luego de la travesía Bertoldo es traído de vuelta a la corte del rey Alboino, a quien le explican que no han podido encontrar el árbol en cuestión. El rey ofrece resistencia: ¡no puede ser que ningún árbol de la península lo satisfaga! Bertoldo confiesa que hay un árbol que le gusta un poco y sólo necesita dos días más para mostrárselo. El rey nuevamente accede y, a los pocos días, Bertoldo regresa a exhibir un pequeño brote: "Me podrán colgar de este árbol, cuando esté listo". Frustrado, Alboino libera al astuto Bertoldo.'

Las asambleas constituyentes suelen poner a los poderes constituidos en la situación de Bertoldo, al ser muchas veces confiados con la difícil tarea de diseñar e implementar las instituciones que deberán limitar su propio poder. Presidentes, ministros y parlamentarios son impiadosamente comisionados a crear y poner en funcionamiento tribunales, entidades de control administrativo y organismos autónomos que, luego de creados, tendrán por propósito hacerles la vida difícil. Piénsese en un parlamento que tiene que crear una Corte Constitucional, que al día siguiente de creada podrá invalidar leyes por él dictadas. ${ }^{2}$ La Constitución le pide a este parlamento, en efecto, elegir el árbol del que será colgado.

En este ensayo exploratorio, construimos sobre esta intuición y sobre la literatura sobre delegación en el diseño constitucional para sugerir que la Convención Constitucional chilena (la 'Convención') deberá tener especial cuidado al crear o reformar instituciones judiciales.

\footnotetext{
'La primera versión de la historia de Bertoldo es la canónica, recopilada por Giulio Cesare Croce en Astuzie sottilissime di Bertoldo de 1606. La segunda está tomada de la película de 1984 Bertoldo, Bertoldino y Cacasenno, dirigida por Mario Monicelli.
}

${ }^{2}$ Tratamos este problema en la Parte III.I de este ensayo, en referencia al caso italiano. 
Deberá tenerlo al diseñarlas y reglamentarlas con el suficiente detalle, a fin de evitar que sus mandatos constitucionales puedan quedar frustrados ante la posible desidia de futuros legisladores o de los múltiples incentivos que pesarán sobre ellos para no implementarlos. Este cuidado, corresponde advertir, deberá ser producto de un esfuerzo algo contranatural: por la composición de la Convención y los temas que seguramente serán prioritarios para sus integrantes, sus incentivos e intereses inmediatos posiblemente estarán alineados en concebir las cuestiones constitucionales en materia judicial de modo minimalista, a fin de alcanzar acuerdos posibles y así atender con mayor detención aquellas temáticas consideradas como prioritarias.

El ensayo procura trabajar en un doble plano. En primer lugar, nos proponemos intervenir en el debate constitucional en curso en Chile, trayendo a colación experiencias comparadas de diseño institucional y reflexionando sobre sus limitaciones. En segundo lugar, intervenimos en la literatura comparada sobre diseño constitucional para advertir sobre las limitaciones de la técnica de delegación en el legislador.

Este trabajo se estructura de la siguiente manera: en la segunda sección, comenzamos por sugerir que es altamente probable que la Convención termine por reglamentar las cuestiones judiciales de modo amplio y general, y evaluaremos esta posibilidad a la luz de la reciente literatura sobre delegación legislativa del diseño de instituciones constitucionales. En la tercera sección, abordamos con algún grado de detalle tres casos de estudio: el de la Corte Constitucional de la Constitución italiana de 1948, el del Consejo de la Magistratura de la Constitución argentina reformada en 1994 y de los tribunales contencioso-administrativos de la Constitución chilena de 1925. En la sección cuarta extraemos lecciones preliminares de estos casos: no obstante las esperables diferencias en procesos tan heterogéneos, las tres experiencias comparten un rasgo fundamental: un diseño constitucional vago o incompleto de instituciones judiciales novedosas que terminó por demorar, poner en peligro o incluso frustrar su implementación por parte del poder legislativo. Finalmente, en la quinta sección entregamos una conclusión a las ideas presentadas a lo largo del ensayo y ofrecemos recomendaciones a los convencionales constituyentes.

\section{DECIDIR NO DECIDIR (Y CUÁNDO NO HACERLO)}

\subsection{Delegar en diseño constitucional}

La Convención tendrá un desafío acuciante. Depositaria de una gran expectativa ciudadana, ella deberá abordar -y procurar resolver- una cantidad prácticamente ilimitada de asuntos sumamente importantes. Las condiciones en las que la Convención se desarrollará elevan la exigencia de este desafío. Chile, como la mayoría de las democracias contemporáneas, ha abierto sus instituciones políticas al pluralismo existente en la sociedad de manera inédita. Así, la Convención deberá dar respuesta a una riquísima variedad de

\footnotetext{
${ }^{3}$ Vid. CADEM (2021b), p. 23 (ubicando a la Convención constituyente como la institución estatal con mayor confianza ciudadana del país).
} 
demandas sociales provenientes de los más diversos grupos. ${ }^{4}$ Dichas demandas, además, ocupan lugares disímiles en las agendas de los constituyentes (entre quienes, además, existe un número significativo de personas con poca o nula vinculación a los partidos políticos que han dominado la esfera pública desde el retorno a la democracia). Por si fuera poco, deberá hacerlo en un tiempo relativamente reducido ${ }^{5}$ y bajo la presión de no volver a la ciudadanía con las manos vacías. ${ }^{6}$ Por último, deberá reunir la cantidad de dos terceras partes de los convencionales en una asamblea sumamente fragmentada y muy heterogénea para aprobar las normas constitucionales, en cuyas mayorías también influirán otras variables inéditas a nivel comparado, como por ejemplo la novedosa composición paritaria de sus integrantes, el cupo reservado a pueblos originarios o la presión de inmediatez que producirán las redes sociales en el proceso.

Manteniendo todos estos elementos fijos, la variable de ajuste más probable será el nivel de detalle con el que se regularán diferentes aspectos de la Constitución. Una Convención con tiempo, recursos y energía limitados, obligada a regular con alto consenso muchísimos aspectos de la vida social y política, probablemente pueda hacerlo sólo con un alto nivel de generalidad en una parte importante de ellos. ${ }^{8}$ Como reza el refrán: quien mucho abarca, poco aprieta.

La generalidad en la redacción de normas constitucionales, por supuesto, no es nueva ni azarosa. En los últimos tiempos, varios autores -entre los que destacan Rosalind Dixon y Tom Ginsburg- han estudiado cómo las asambleas constituyentes con frecuencia 'deciden no decidir' en muchos temas, ${ }^{9}$ dejando importantes decisiones institucionales al arbitrio de una futura legislatura. Esta ‘delegación’ en el poder constituido puede darse de diversas formas:

${ }^{4}$ GinsburG (2010), p. 71 (explicando que las constituciones con el tiempo se han hecho cada vez más largas); LAW \& VEERSTEG (2011), p. 1194-98 (documentando la expansión del catálogo de derechos para hacer frente a demandas cada vez más crecientes de la ciudadanía).

${ }^{5}$ El artículo 137 de la Constitución chilena establece que la Convención deberá redactar y aprobar un texto constitucional dentro del plazo de nueve meses, el que podrá ser prorrogado una sola vez por otros tres meses adicionales.

${ }^{6} \mathrm{Al}$ tenor del inciso segundo del artículo 135 de la constitución, en caso que la Convención no tenga éxito en su empresa constituyente, ella permanecerá plenamente vigente. Es de prever que los constituyentes harán todo lo posible por evitar este desenlace: además de un derroche de recursos mayúsculo, sería defraudar las expectativas de los ciudadanos a quienes se prometió una nueva constitución como modo privilegiado de canalizar las demandas que dieron lugar al estallido social de 2019.

' La inmediatez de las redes sociales, mientras puede abrir canales de comunicación entre representantes y representados, también puede poner en riesgo los inevitables tiempos que requiere la reflexión y la deliberación democráticas. Al respecto puede leerse el trabajo de MING-SUNG (2019). Las redes sociales pueden afectar la deliberación democrática de formas algo inesperadas y sobre las cuales no tenemos experiencia en procesos constituyentes. Por ejemplo, existe evidencia empírica de que ver debates presidenciales mientras se lo está simultáneamente comentando y siguiendo a través de las redes sociales reduce el conocimiento del espectador sobre los asuntos de campaña (comparado con ver el debate sin contacto con redes sociales). Véase GOTTFRIED et al. (2017).

${ }^{8}$ GinsburG (2010), pp. 76 y ss. (desarrollando el trade-off entre el "alcance" de los asuntos regulados por la constitución y su nivel de "detalle").

${ }^{9}$ El término pertenece a DIXON y GINSBURG (2011a). 
regulando aspectos con un alto nivel de generalidad, ${ }^{10}$ acumulando pretensiones incompatibles con la esperanza que los legisladores futuros resuelvan las tensiones que no pudieron resolverse durante la constituyente, ${ }^{11}$ simplemente guardando silencio acerca de la cuestión, ${ }^{12} \mathrm{o}$ -con cada vez mayor frecuencia- explicitando que la cuestión será regulada "por ley" ${ }^{13}$ a veces sujetas a mayorías especiales.

Estas diferentes técnicas de delegación son tentadoras y es indudable que frecuentemente existen buenas razones para recurrir a ellas. Por ejemplo, Dixon y Ginsburg recomiendan deferir cuestiones al legislador cuando en una asamblea constituyente existen asimetrías de información, incentivos a la abstención o 'pasiones constitucionales' entre las partes en las negociaciones constitucionales que pueden llevar a que los costos de transacción para alcanzar un acuerdo sobre cuestiones constitucionales sean desproporcionadamente altos. Estos problemas de negociación hacen particularmente recomendable esta delegación cuando, como ocurre en el caso chileno, las asambleas estén sujetas a limitaciones temporales. ${ }^{14}$ Además, dicen Dixon y Ginsburg, la deferencia al legislador también puede disminuir los costos del error de asambleas con información imperfecta acerca de futuros avances sociales, políticos o tecnológicos. En estas circunstancias, deferir a un futuro legislador con mayores capacidades epistémicas puede ser una estrategia recomendable. ${ }^{15}$

Esta delegación al legislador, adicionalmente, puede presentar ventajas para la construcción de sentido en democracias constitucionales cada vez más heterogéneas. Dejar la regulación constitucional de algunos asuntos álgidos a su solución política puede permitir el florecimiento de 'consensos superpuestos ${ }^{16}$ que, si bien no son los acuerdos completos que puedan satisfacernos en lo teórico, sí son mejores que su alternativa (es decir, que no haya ningún acuerdo, siquiera mínimo). ${ }^{17}$ Además, una regulación mínima puede permitir canalizar el conflicto político de modo que distintos sectores encuentren en la constitución un marco dentro del cual plantear sus objetivos. De este modo, que la filósofa Chantal Mouffe llama

\footnotetext{
${ }^{10}$ Ginsburg y Dixon, por ejemplo, afirman que la vaguedad constitucional actúa como sustituto de la delegación expresa en el constituyente (Ibídem, p. 652).

${ }^{11}$ Por ejemplo, veáse Gargarella (2016). Una mención similar a esta estrategia en el contexto sudafricano en DiXON y GinsBurg (2011b).

${ }^{12}$ Gargarella (2016), pp. 50)-51.

${ }^{13}$ Esta delegación suele hacerse mediante lo que DiXON y GinSBURG llaman "cláusulas "por ley" (“by law clauses"), mediante las cuales el constituyente explícitamente delega cuestiones en la próxima legislatura (DIXON y GiNSBURG (2011a), p. 637).

${ }^{14}$ DiXON y Ginsburg (2011a), p. 638.

${ }^{15}$ Ibídem, pp. 643-646.

${ }^{16}$ Para parafrasear la expresión de John Rawls. El constitucionalista Cass Sunstein habla de "acuerdos incompletamente teorizados" para describir estas situaciones en las cuales hay acuerdo sobre la regla a adoptar pero no sobre las razones que llevan a hacerlo. Si bien está pensando fundamentalmente en los razonamientos detrás de fallos judiciales, Sunstein sugiere que este tipo de acuerdos puede posibilitar la sanción de constituciones que de otro modo sería imposible (véase SUNSTEIN (2002), p. 56).
}

${ }^{17}$ Este argumento es realizado en Gargarella (2016). 
agonal, ${ }^{18}$ los diferentes actores políticos lucharán por darle a la constitución un sentido acorde con sus expectativas y valores, pero sin dejar de sostener a la Constitución misma. ${ }^{19}$ Piénsese, por ejemplo, en cómo distintos sectores en los Estados Unidos disputan el sentido de la cláusula constitucional sobre protección igualitaria contenida en la décimo cuarta enmienda (Equal Protection Clause), al adjudicarle sentidos contrapuestos: mientras unos sostienen que ésta exige acciones afirmativas que privilegien a ciertos grupos históricamente desaventajados en la asignación de lugares en trabajos y universidades, otros mantienen que obliga a las autoridades públicas a ser 'ciegas al color', sin permitir tener factores como la raza o el género en cuenta al momento de otorgar lugares o beneficios. ${ }^{20} \mathrm{Si}$ bien esta disputa sobre el significado de la Constitución es particularmente estruendosa en los Estados Unidos (en los que esta disputa constitucional adquiere un cariz y un fervor cuasi religiosos), ${ }^{21}$ se podría aspirar a algo similar para Chile: que una constitución exitosa permita a todos los sectores de la política democrática reivindicarla como la fuente de sus valores y programas. Sin embargo, nuestro ensayo apunta precisamente a moderar el entusiasmo por estas cláusulas en ciertas cuestiones de diseño judicial. Si bien las cláusulas delegativas en general pueden ser provechosas para la gobernanza democrática, en algunos casos pueden suponer riesgos para ella.

Comencemos por efectuar una importante distinción: el constitucionalista estadounidense Sanford Levinson ha diferenciado entre la constitution of conversation ('constitución de la conversación') y la constitution of settlement (que puede traducirse como 'constitución de lo zanjado' $)^{22}$. La constitución de la conversación, como en los ejemplos anteriores, apunta a dejar abierto un marco que permita desarrollar la disputa permanente por el sentido de los valores en la vida en común. Esta apertura es justamente lo que permite a la constitución ser un texto viviente y que el derecho constitucional pueda ser entendido como un diálogo entre generaciones. ${ }^{23}$ La constitución de lo zanjado, por el contrario, apunta a dejar algunas cuestiones por fuera de la discusión constitucional. Por ejemplo, en el caso chileno, el presidente debe tener treinta y cinco años de $\operatorname{edad}^{24}$ y ser electo en doble vuelta en caso de no obtener mayoría absoluta, ${ }^{25}$ el mandato de los diputados dura cuatro años y ellos no podrán ser reelectos en más de dos oportunidades, ${ }^{26}$ etc.

\footnotetext{
${ }^{18}$ Véase por ejemplo MOUFFE (2016).

${ }^{19}$ Este argumento es realizado con fuerza en POST y SIEGEL (2013).

${ }^{20}$ Compárese, por ejemplo, los votos de mayoría y los de disidencia en Parents Involved in Community Schools v. Seattle School District No. 1 (2007), en particular en cuanto disputan si la decimocuarta enmienda es, o no, "ciega al color".

${ }^{21}$ La idea de que la lectura e interpretación de la Constitución norteamericana es un fenómeno comparable al religioso es antigua, aunque tal vez su desarrollo más acabado se encuentre en LEVINSON (2011).

${ }^{22}$ LEVINSON (2012).

${ }^{23}$ Véase ACKERMAN (2018) (“... the dialogue between the generations that is constitutional law”); STRAUSS (2010).

${ }^{24}$ Art. 25 de la Constitución Chilena.

${ }^{25}$ Id. art. 26.

${ }^{26}$ Id. art. 47.
} 
Las cuestiones de la constitución de lo zanjado no están sujetas a discusión sobre su significado ni a interpretaciones acerca de una solución correcta. ${ }^{27}$ Por el contrario, es precisamente el hecho de que ya estén determinadas de una vez el que nos libera de tener que discutirlas nuevamente en cada momento y nos permite así orientar nuestra atención a deliberaciones de política sustantiva. ${ }^{28}$ Tal como las reglas del ajedrez, ellas permiten establecer un marco que en definitiva posibilita que podamos jugar a algo. ${ }^{29}$ Para las reglas de la constitución de lo zanjado no corre lo dicho sobre las ventajas de la ambigüedad y la delegación: aquí conviene ser lo más preciso y estricto posible, precisamente para evitar tener discusiones donde no deberíamos tenerlas.

\section{$1.2{ }_{\mathrm{d} P o r}$ qué centrarnos en instituciones judiciales?}

Como adelantamos, nos proponemos discutir precisamente la cuestión de la delegación en un aspecto central de la constitución de lo zanjado: la regulación de instituciones judiciales. ${ }^{31}$ Argumentamos que la Convención deberá hacer un esfuerzo adicional al esperable en alcanzar acuerdos que definan los aspectos estructurales de cuestiones judiciales centrales para la democracia constitucional. La experiencia comparada -y también la chilena, como veremos más adelante- nos provee de múltiples ejemplos en los cuales los constituyentes, por distintos motivos, diseñaron instituciones judiciales sin el suficiente detalle, llevando a resultados indeseables como la demora en su creación, ${ }^{32}$ su cooptación por parte de la política partidaria ${ }^{33}$ o, más llanamente, que nunca hayan llegado a existir. ${ }^{34}$

Todo parece presagiar que, de no mediar un esfuerzo consciente en contrario, esta aproximación minimalista podría ser el destino de ciertas cuestiones relativas a la organización y funcionamiento de la judicatura en la futura constitución chilena. Alrededor de esta cuestión converge una tríada de fuerzas en direcciones divergentes: i) es un asunto al que la ciudadanía y los constituyentes no han prestado especial atención (al menos hasta ahora), ii) sin perjuicio de su importancia capital en las democracias constitucionales contemporáneas, y sobre el cual,

\footnotetext{
${ }^{27}$ LEVINSON (2011) p. 17.

${ }^{28}$ Sobre la idea de que las normas constitucionales rígidas pueden ser liberadoras al permitir debatir sobre política sustantiva en lugar de rediscutir constantemente las reglas de juego, véase HoLMES (1988), p. 231 ("Cuando entran al cuarto oscuro, los votantes deciden quién será presidente, pero no cuántos presidentes habrá”).

${ }^{29}$ El ejemplo también es de HoLmes (1988), p. 227.

${ }^{30}$ La propia Dixon, que en general es favorable a dejar cuestiones abiertas a la futura construcción judicial, reconoce que "las cláusulas constitucionales diseñadas para sentar las reglas procedimentales básicas de la democracia [...] deben ser relativamente específicas e inequívocas para cumplir sus funciones” (DIXON (2015)).

${ }^{31}$ En este ensayo, usamos la expresión "instituciones judiciales” en un sentido amplio para referirnos tanto a tribunales propiamente dichos como también a instituciones que participan del gobierno de la judicatura.

${ }^{32}$ Véase infra Parte III.1.

${ }^{33}$ Véase infra Parte III.2.

${ }^{34}$ Véase infra Parte III.3.
} 
iii) la Convención estará obligada a llenar el vacío causado por la "hoja en blanco" sobre la cual escribirá la nueva constitución.

Primero, los asuntos judiciales no han recibido una gran atención por parte de la ciudadanía o los constituyentes como para suponer que se tratarán de un tema prioritario en el trabajo de la Convención. ${ }^{35}$ Diversos antecedentes permiten intuir que la ciudadanía tiene escaso interés en estos temas. Por ejemplo, una de las principales mediciones del país refleja que sólo un 5\% de los encuestados considera que las cuestiones judiciales son uno de los principales temas de la Convención. ${ }^{36}$

Similar desinterés puede inferirse de la lectura de los programas que los Convencionales Constituyentes presentaron al Servicio Electoral: más de la mitad de quienes resultaron electos para redactar la futura constitución poco o nada proponen en esta materia. Entre los restantes, hay propuestas sumamente innovadoras en cuanto a diseño judicial: cerca de un quinto -de carácter transversal- propone la creación de un consejo a cargo de la administración y los aspectos logísticos del poder judicial, a fin de separar estas tareas de las labores propiamente jurisdiccionales. ${ }^{37}$ Asimismo, muchos proponen la creación de tribunales contenciosoadministrativos bajo diversas modalidades. ${ }^{38}$ Sin embargo, en todos estos casos las propuestas planteadas adolecen de una excesiva generalidad y, casi en su totalidad, carecen de elementos que permitan vislumbrar cómo ellas se concretarán en diseño institucional. ${ }^{39}$

Existe tal vez una importante excepción sobre esta escasa atención de parte de los convencionales respecto de temas judiciales: el tribunal constitucional. Son varios los que abogan por introducir profundas reformas a este tribunal, llegando incluso a sugerir su reemplazo o eliminación. ${ }^{40}$ Mientras algunos convencionales conservadores consideran imprescindible mantener el control preventivo de constitucionalidad de las leyes, ${ }^{41}$ otros más

\footnotetext{
${ }^{35}$ En sentido coincidente, SIERRA (2020), p. 22 (explicando que los temas judiciales no han recibido particular atención en el debate constitucional). En términos similares, SOTO incluye estos temas entre los 'debates menos intensos...pero importantes'. SOTO (2020).

${ }^{36}$ En particular, la respuesta atiende al Tribunal Constitucional, que se ubica en el décimo primer lugar de prioridades. Véase CADEM (2021a).

${ }^{37}$ Véase, a modo de ejemplo, las propuestas de la Lista del Pueblo y de los partidos Socialista, Evolución Política, Revolución Democrática y del Partido Por la Democracia.

${ }^{38}$ Véase, por ejemplo, las propuestas del Instituto Libertad (adoptado por algunos constituyentes de Renovación Nacional) y del Partido Socialista.

${ }^{39}$ En este sentido, José Francisco García ha planteado la necesidad de transitar desde planteamientos genéricos hacia propuestas específicas respecto de los temas que se han instalado como centrales en la discusión constitucional y que, por lo tanto, podrían transformarse en nudos críticos. Uno de los temas que el autor menciona como centrales es justamente el de la justicia constitucional. GARCÍA (2021).

${ }^{40}$ Véase, por ejemplo, la propuesta del Partido Comunista (reemplazo completo) o de Ivanna Olivares (eliminar el Tribunal Constitucional y transferir sus competencias a la Corte Suprema).

${ }^{41}$ En el documento de la Unión Demócrata Independiente 'Nuestra Visión Constitucional' se afirma que "Is/in un control preventivo (que puede ser solo facultativo) no tiene sentido tener una Constitución, ya que, por ley simple, el Congreso se puede "saltar" la Constitución”. (punto 6). UDI (2021).
} 
progresistas abogan por la eliminación del Tribunal. ${ }^{42}$ Esta controversia en torno a la justicia constitucional supone la situación opuesta a la anterior, ya que sí puede hablarse de un interés de los convencionales sobre la materia. Sin embargo, puede que igualmente se llegue a un resultado idéntico: ante la imposibilidad de acordar en un tema tan importante como controversial, es posible que también se postergue esta discusión y sea simplemente delegada al legislador.

Segundo, las instituciones judiciales están adquiriendo un peso creciente en la gobernanza de las democracias contemporáneas en un fenómeno que a veces se denomina como juristocracia. ${ }^{43}$ No prestarles atención al momento del diseño constitucional es esconder la cabeza en la arena: el rol protagónico que han adquirido los tribunales en las últimas décadas los colocará tarde o temprano en el centro de la atención pública. Esta 'judicialización' de la política en todo el mundo ha ampliado el alcance protagónico de los tribunales ya no sólo a cuestiones polémicas sobre adjudicación de derechos sociales o de políticas públicas, sino a lo que Ran Hirschl denomina la 'mega política', es decir, a aquellos asuntos de absoluta y máxima importancia política que a menudo definen los clivajes y dividen los grupos antagónicos sobre los cuales se estructura una comunidad política. ${ }^{4}$

De esta manera, en muchas de las democracias más importantes del mundo -sea por su tamaño, hegemonía cultural o por su tradición- los tribunales han comenzado a resolver cuestiones de inusitada importancia política. Por ejemplo, la Corte Suprema norteamericana determinó el resultado de la elección presidencial de 2000 al resolver Bush v. Gore. En Brasil, el Supremo Tribunal Federal impidió la participación del candidato favorito según las encuestas en las elecciones presidenciales de $2018 .{ }^{46}$ En Miller II, la Corte Suprema británica criticó fuertemente al Primer Ministro por procurar limitar el debate parlamentario en la antesala de la salida del Reino Unido de la Unión Europea. ${ }^{47}$ Más recientemente, en Edelstein la Corte Suprema de Israel impidió que un grupo parlamentario legislara para impedir al Primer Ministro presentarse nuevamente a elecciones generales. ${ }^{48} \mathrm{Y}$ así, son cada vez más frecuentes en todo el mundo las actuaciones de tribunales superiores que, aprovechando la tenue línea que separa el derecho constitucional de la política, determinan irremediablemente el curso del ciclo político.

Este fenómeno ciertamente no es ajeno a la realidad chilena. Si bien históricamente los tribunales chilenos se mostraron indiferentes a las grandes disputas y conflictos políticos que

\footnotetext{
${ }^{42}$ En el documento del Frente Amplio 'Ruta Constituyente' se propone “... terminar con el actual Tribunal Constitucional, estableciendo una nueva institucionalidad paritaria que garantice los derechos fundamentales y la aplicación efectiva de la nueva Constitución" (punto 3.a). Frente Amplio (2021).

${ }^{43}$ Hirschl (2004). A mayor abundamiento, véase Stone (2000); TATe y Vallinder (1997). Para América Latina, véase GONZÁLEZ-OCANTOS et al. (2021).

"HIRSCHL (2008), p. 11: 93-118.

${ }^{45}$ Bush v. Gore, 531 U.S. 98 (2000). Véase Balkin (2001); Chemerinsky (2000-2001).

${ }^{46}$ RESENDE y Ribas (2018).

${ }^{47} R$ (Miller) $v$ The Prime Minister and Cherry v Advocate General for Scotland ([2019] UKSC 41).

${ }^{48}$ WEILL (2021).
} 
tenían lugar en la sociedad chilena, hoy tienen un lugar gravitante como actores políticos. ${ }^{49}$ Las recriminaciones cada vez más frecuentes contra los llamados supremazos ${ }^{50}$ y la tercera cámara legislativa ${ }^{\text {SI }}$-forma de denominar críticamente las decisiones de la Corte Suprema y las actuaciones del Tribunal Constitucional- pueden entenderse como una manifestación de lo anterior. Esta creciente importancia de la judicatura en la política chilena sin embargo contrasta con la escasa -por no decir casi nula- atención que se le ha prestado al diseño de lo judicial. ${ }^{52}$

Tercero -y de modo algo contraintuitivo-, estas situaciones (falta de interés generalizado con propuestas divergentes en alguna cuestión específica sumadas a la enorme importancia del asunto) no podrán traducirse, como sería esperable en otras circunstancias, en la simple conservación del status quo. Si bien las normas constitucionales que regulan las cuestiones judiciales son en su mayoría de antigua data (algunas remontándose a 1823), uno de los ejes centrales del acuerdo que dio inicio al proceso constituyente involucra escribir una nueva constitución sobre una hoja en blanco. Esto obliga a que los convencionales deban decidir algo. A diferencia de lo que ocurriría en una simple reforma constitucional que se construye sobre el texto anterior, aún mantener el texto vigente deberá ser una decisión consciente por parte de los constituyentes.

En estas circunstancias, podría parecer atractivo seguir el consejo de Dixon y Ginsburg de delegar en parte importante estas materias al legislador. Este camino podría ahorrar a los constituyentes tiempo y energía que desean aplicar en materias de su interés y de los ciudadanos a quienes representan, dejándolo a un futuro legislador con más recursos e incentivos para regular esta materia de modo adecuado. De hecho, la materia judicial es una de las Dixon y Ginsburg reportan como más frecuentemente delegada al legislador a nivel comparado. ${ }^{53}$

En esta línea, hay quienes -como Lucas Sierra- que plantean que debe buscarse un diseño constitucional minimalista en materia judicial, fundándose en la conveniencia de "reducir la intensidad constitucional de la regulación de la judicatura...” atendido su “... creciente detalle regulatorio". "Aunque en otro contexto, en términos similares se pronunció la Mesa de Trabajo convocada por el Ministerio de Justicia en 2018 para evaluar reformas al Poder Judicial. En ella, una de las conclusiones apunta a que "[e]l diseño normativo actual es insuficiente principalmente porque, por un lado, la CPR parece tener un desarrollo excesivo...” de ciertos mecanismos de nombramiento judicial, “... sin que resulte del todo justificado el empleo de la CPR para reglamentar cuestiones que obviamente son de discernimiento

\footnotetext{
${ }^{49}$ Couso y Hilbink (2011).

${ }^{50}$ Para el estudio más completo de este fenómeno en el Poder Judicial, véase García y VerdugO (2013). Más recientemente, SOTO (2020), pp. 199-200.

${ }^{51}$ Por ejemplo, véase Fernando Atria y Constanza Salgado, El TC como tercera Cámara (serie de columnas), El Mostrador.

${ }^{52}$ Aldunate (2016), p. 123.

${ }^{53}$ DixOn y Ginsburg (2011a), 660.

${ }^{54}$ SIERRA (2020), pp. 41-2.
} 
legislativo. ${ }^{5_{5}}$ Una estrategia efectiva para lograr el propósito explicitado en uno y otro caso sería justamente entregar algunas cuestiones judiciales actualmente en la Constitución a la regulación legislativa. Sin embargo, los casos expuestos en la próxima sección representan advertencias contra esta tesitura.

\section{TARDE, MAL Y NUNCA: ITALIA, ARGENTINA Y CHILE}

¿Puede aprender algo la Convención de otros procesos constituyentes en el diseño de cuestiones judiciales? Creemos que sí. Ofrecemos aquí la descripción de tres procesos con una estructura común: una incompleta regulación constitucional llevó al fracaso o puso en peligro instituciones judiciales inéditas que fueron creadas en dichos procesos: la de la Corte Constitucional en la Constitución italiana de 1948, la del Consejo de la Magistratura en la reforma constitucional argentina de 1994 y la de los tribunales administrativos en la Constitución chilena de 1925.

Nuestros casos, sin embargo, difieren en prácticamente todo lo demás. Como puede apreciarse a simple vista, corresponden a épocas y contextos diferentes. Los procesos constituyentes en cada caso también difieren: la Constitución chilena de 1925 fue redactada en luego de un quiebre institucional en el que los militares y el presidente Alessandri Palma promovieron un proceso constituyente a cargo de una comisión con escasa deliberación interna ${ }^{56}$ la Constitución italiana de 1948 fue producto de una asamblea constitucional que debía encontrar un acuerdo entre comunistas, socialistas y demócratas cristianos en un momento de efervescencia política tras la salida del fascismo; ${ }^{57}$ la reforma constitucional argentina, si bien producto de una convención electa, no fue el resultado de una movilización popular sino de un pacto de élites políticas con el objetivo primario de permitir la reelección del entonces presidente. ${ }^{58}$

Son justamente estas diferencias las que permiten resaltar las similitudes entre los procesos. $^{59}$ Como veremos, en todos los casos reseñados un defectuoso diseño o reglamentación a nivel constitucional llevó a obstáculos similares en su implementación legislativa que deberían, en lo posible, ser evitados en el proceso constituyente en curso. Los llamaremos, tal vez de modo pesimista, 'tarde', 'mal' y 'nunca'.

\subsection{Tarde: Italia 1947}

\footnotetext{
${ }^{55}$ Informe Final con las Conclusiones y Recomendaciones de la Mesa Interinstitucional sobre Nombramiento de Jueces, 10 de enero de 2019, p.11.

${ }^{56}$ DONOSO (1976), p.280 ( "En dicha Comisión no se votaba, más bien se recogían y aunaban opiniones en cuanto fueran compatibles con la idea central de poner límites razonables a la intervención parlamentaria -y por ende partidarista- en la administración del Estado. ”.

${ }^{57}$ Véase en general ACKERMAN (2019), pp. 131-156.

${ }^{58}$ Véase infra Parte III.2.

${ }^{59}$ Sobre la metodología de los 'casos más diferentes', véase HiRSCHL (2005), pp. 139-142.
} 
Algunos de los aspectos de la asamblea constituyente italiana de 1947 tienen un aire familiar con la chilena de 2021. La asamblea italiana -producto de un plebiscito durante un periodo de intensa movilización social- fue integrada por un mosaico de partidos radicalmente opuestos que al mismo tiempo sentían la presión de entregar un texto constitucional a la ciudadanía en un periodo de tiempo acotado. ${ }^{60}$ Siendo así, no es sorprendente que al acercarse su fecha de expiración la asamblea haya decidido dejar algunos aspectos sin resolver con tal que los italianos pudieran inaugurar el año 1948 con una nueva constitución.

Uno de los aspectos dejados a la reglamentación futura fue el diseño de la Corte Constitucional. La Corte -cuya incorporación a la arquitectura constitucional italiana había sido agriamente discutida en el seno de la asamblea- fue dejada para las últimas semanas del debate. ${ }^{61}$ Carente de tiempo y tal vez imposibilitada de lograr acuerdos durante el exiguo plazo restante, la asamblea simplemente esbozó en lápiz los contornos generales de la institución; el resto debía ser coloreado por el Parlamento en una ley especial. ${ }^{62}$ Todo cuanto decía el artículo 135 de la Constitución aprobada es que la Corte Constitucional estaría integrada por "quince jueces nominados en un tercio por el Presidente de la República, un tercio por el Parlamento en sesión común y un tercio por las supremas magistraturas ordinarias y administrativas". Además, el artículo establecía ciertas calificaciones profesionales mínimas para acceder al cargo, el cual duraría doce años no renovables, y que la Corte elegiría un presidente de entre sus miembros. ${ }^{63}$

La regulación constitucional dejaba múltiples aspectos centrales librados a la regulación legislativa, como los efectos de la declaración de inconstitucionalidad, la relación de la Corte con los jueces ordinarios y, centralmente en lo que aquí importa, el modo de designación de sus integrantes. El Parlamento pronto se daría cuenta de que su tarea no era meramente de reglamentación o implementación de normas constitucionales establecidas sino, más dramáticamente, "completar las piezas faltantes del propio diseño constitucional”. ${ }^{64}$

Los resultados de la delegación no fueron los esperados. En 1955, el influyente jurista y constituyente Piero Calamandrei denunciaba amargamente que su ensayo sobre el 'inmovilismo constitucional' de la época debió haberse intitulado Cómo se hace para deshacer una Constitución. ${ }^{65}$ En efecto, la ley que reglamentó la Corte fue dictada recién en 1953 y la designación de la primera camada de jueces constitucionales se realizó recién en 1956.

\footnotetext{
${ }^{60}$ La Asamblea se dio originalmente un periodo de tiempo de ocho meses, que fue prorrogado dos veces hasta llegar a un total de poco más que un año y medio (véase el Decreto Legislativo Luogotenenziale del 16 de marzo de 1946 n. 98, art. 4 y sus prórrogas mediante las leyes constitucionales 1/1947 y 2/1947).

${ }^{61}$ BARSOTTI et al (2015), pp. 17-18.

${ }^{62}$ Estas expresiones pertenecen a Piero Calamandrei, Ostruzionismo di maggioranza, en CALAMANDREI (1966), p. 556.

${ }^{63}$ Algunos de estos aspectos fueron modificados luego por la ley constitucional 2/1967.

${ }^{6 t}$ BARSOTTI et al (2015), p. 21.

${ }^{65}$ Calamandrei (1955), p. 211.
} 
Dada la premura con la que se sancionó la Constitución, esta demora exige una explicación. Se han intentado al menos dos.

La explicación predominante ${ }^{66}$ es la propuesta contemporáneamente por el propio Calamandrei, figura clave en la incorporación de la Corte a la Constitución como constituyente y en su reglamentación como diputado en la Primera Legislatura. Calamandrei denunció el obstruccionismo de mayoría de la gobernante Democracia Cristiana. ${ }^{67} \mathrm{El}$ partido de gobierno, siendo la primera minoría en la asamblea constituyente en una época en la que había incertidumbre sobre el próximo resultado electoral, había exitosamente promovido la creación de la Corte frente al escepticismo de los socialistas y comunistas, quienes veían en este órgano una "bizzarria" pergeñada para invalidar futuras conquistas de mayorías obreras. ${ }^{68}$ Ahora, con una cómoda mayoría en el Parlamento, la Democracia Cristiana ya no tenía urgencia en colgar la espada de Damocles sobre su propia cabeza. ${ }^{69}$ Así, durante años, los democristianos arrastraron lentamente el trámite legislativo con el plan de que la Corte no se instalase mientras fueran gobierno. Cuando la presión se hizo insoportable, de todos modos, la mayoría democristiana intentó un último truco: forzando la interpretación de la Constitución, propuso que los cinco miembros nombrados por el Presidente de la República lo fueran a propuesta del Ministerio de Justicia. ${ }^{70}$ Además, propuso que los cinco miembros correspondientes a la Legislatura fueran electos por mayoría simple. Con este doble truco, la Democracia Cristiana se aseguraría diez de los quince miembros de la Corte.

El escándalo fue de proporciones. El Presidente Luigi Einaudi -un liberal defensor del control de constitucionalidad desde antes de la Marcha sobre Roma de 1922- amenazó con renunciar a su cargo si el gobierno no deponía su plan de control sobre la Corte. Finalmente, se reconoció que el Presidente podía nombrar a sus cinco miembros autónomamente y se exigió una mayoría de dos tercios de la Legislatura (que descienden a tres quintos tras tres votaciones frustradas) para nombrar a los miembros de designación parlamentaria. Sin embargo, aún había una trampa: pocos meses después se realizarían las elecciones parlamentarias bajo la legge truffa (o 'ley trampa'), según la cual el partido que obtenía más de la mitad de los votos válidos se quedaría con el $65 \%$ de los asientos en el Parlamento. Si el optimismo de la Democracia Cristiana se confirmaba en las urnas, gozaría de la mayoría necesaria para nombrar a cinco jueces por doce años (y, especulaba Calamandrei, para volver

\footnotetext{
${ }^{66}$ Según Andrea Simoncini, quien disiente con esta versión, la idea del obstruccionismo de mayoría se transformó en la "clave de lectura" de gran parte de los juristas acerca del retraso en la activación de la Corte, véase SIMONCINI (2006).

${ }^{67}$ Lo hizo en una serie de artículos publicados en su revista Il Ponte, recopilados luego en CALAMANDREI (1955).

${ }^{68}$ El influyente líder comunista Palmiro Togliatti afirmó que la Corte era una “bizzarria” introducida por temor a una futura mayoría obrera (véase su discurso en la sesión vespertina del 11 de marzo de 1947, disponible en https://www.nascitacostituzione.it/05appendici/01generali/03/index.htm?(008.htm\&2).

${ }^{69}$ Si bien la Constitución parecía dejar, en su cláusula transitoria VII, la posibilidad de declarar la inconstitucionalidad de las leyes a los jueces ordinarios, estos abdicaron rápidamente de ejercer dicha facultad de modo significativo (véase BARSOTTI et al. (2015), p. 26).

${ }^{70}$ En el diseño republicano italiano, el Presidente es una figura mayormente ceremonial en cabeza de una figura de consenso y prestigio pero con acotadas funciones de gobierno.
} 
a pulsear con el Presidente Einaudi por la designación de los jueces correspondientes al Presidente de la República). ${ }^{71}$ Nos quedamos sin conocer este escenario: finalmente la Democracia Cristiana obtuvo el 49,8\% de los votos y debió negociar con la oposición los jueces a designar. ${ }^{72}$ Este diseño, finalmente, permitió una Corte que ha gozado de amplia legitimidad en Italia.

Sin embargo, estudios más recientes descartan el 'obstruccionismo de mayoría' como explicación y, en su lugar, apuntan a desorientación y desacuerdos genuinos en torno a la organización del tribunal. La Corte Constitucional era una novedad en el régimen constitucional italiano (y aún europeo), acostumbrado a una constitución flexible a la supremacía parlamentaria. Pretender que el Parlamento resolviera esta cuestión rápidamente como si fuera una cuestión legislativa común, dicen, sería subestimar la densidad de la discusión institucional a la que se enfrentaron. ${ }^{74}$

En todo caso, cabe preguntarse por qué a pesar de estos sobresaltos iniciales, la Corte Constitucional italiana fue finalmente puesta en funcionamiento y gozó por las décadas siguientes de estabilidad y legitimidad. Bruce Ackerman se lo atribuye a las cualidades de estadista de algunos de los actores involucrados. Tanto el Presidente Einaudi como el Primer Ministro Alcide De Gasperi eran hombres en el otoño de sus carreras políticas. Ambos habían combatido el fascismo desde el exilio o la prisión y habían comprendido y defendido la importancia de una corte constitucional para prevenir los excesos mayoritarios. No iban a dejar pasar la oportunidad de consagrar estos ideales constitucionales por ventajas políticas de corto plazo. ${ }^{75}$ Una vez instalada, sostiene Ackerman, la Corte logró representar el "momento constitucional” italiano y así preservarse de intentos de captura por parte de sucesivas mayorías circunstanciales. $^{76}$

La Corte Constitucional italiana logró ser una institución exitosa a pesar de -y no debido a- la frugalidad de su reglamentación constitucional. Corresponde reflexionar acerca de si, cualesquiera que hayan sido las circunstancias que posibilitaron su éxito, ellas estarán presente en las instituciones chilenas que deberán implementar la constitución que se sancionará el próximo año. Para pensarlo, tal vez convenga detenerse en un ejemplo menos auspicioso, como el que analizamos a continuación.

\subsection{Mal: Argentina 1994}

\footnotetext{
${ }^{71}$ Calamandrei (1966), pp. 586-595.

${ }^{72}$ ACKERMAN (2019), p. 151.

${ }^{73}$ Esto puede apreciarse en el hecho que, a pesar de haberse opuesto con firmeza durante la Asamblea constituyente, comunistas y socialistas rápidamente comenzaron a reclamar por la instalación de la Corte Constitucional y a realizar planteos ante ella.

${ }^{74}$ Esta es la posición de SimONCINI (2006).

${ }^{75}$ Véase ACKerman (2019), pp. 149-150.

${ }^{76}$ ACKERMAN (2019), p. 156.
} 
La reforma constitucional argentina de 1994 fue el producto de un acuerdo entre los partidos mayoritarios de aquel momento: el gobernante Partido Justicialista y la opositora Unión Cívica Radical. La reforma nació sin épica alguna. El presidente Menem deseaba reformar la Constitución de 1853, que le impedía ser reelecto. La oposición, liderada por el ex presidente Raúl Alfonsín, terminó concediéndoselo para evitar el riesgo de que Menem forzara la interpretación de la cláusula de reforma constitucional y lo hiciera por sí mismo. Así nació el llamado 'Pacto de Olivos', por el cual se permitiría la reelección presidencial a cambio de incluir también una serie de reformas institucionales que atenuarían lo que se consideraba era un régimen hiperpresidencialista. ${ }^{77}$

Entre las múltiples reformas destinadas a disminuir el poder del presidente, algunas tenían que ver directamente con el Poder Judicial. Había cierto consenso en que el gobierno de Menem había abusado seriamente de sus facultades constitucionales para entrometerse en la Justicia. En 1990, el Congreso amplió la Corte Suprema de cinco a nueve miembros, lo que, sumado a una renuncia en protesta, le permitió a Menem aprobar cinco nombramientos de jueces supremos en una breve sesión de tan sólo siete minutos. ${ }^{78}$ Estos jueces conformarían lo que luego se llamaría la mayoría automática menemista. Poco tiempo después, el Congreso realizó una reforma procesal que, entre otras cosas, duplicó la cantidad de juzgados federales de instrucción de Buenos Aires, permitiéndole nombrar a media docena de jueces, muchos de los cuales serían altamente cuestionados tanto por su falta de calificaciones técnicas como por su cercanía al gobierno. Por último, rompiendo una tradición no escrita, Menem nombró al Procurador General (cabeza de los fiscales federales) mediante decreto simple, sin someterlo a confirmación del Senado. ${ }^{79}$

Esta calamitosa situación del Poder Judicial fue objeto de atención en la convención constituyente, que reformó los artículos constitucionales que regulaban esas tres cuestiones. Sin embargo, las reformas proporcionaron un diseño deficiente o incompleto de estas instituciones judiciales, poniéndolas nuevamente en una situación de fragilidad. A la fecha de entrega de este trabajo, se encuentra en discusión tanto el número de miembros de la Corte como las mayorías necesarias para designar a los titulares del Ministerio Público Fiscal. ${ }^{80}$ Sin embargo, en este ensayo nos concentraremos en la institución más novedosa que introdujo la reforma de 1994 y la que más problemas trajo: el Consejo de la Magistratura.

\footnotetext{
${ }^{77}$ El propio ALFONSÍN (1996) explica este proceso.

${ }^{78}$ Una segunda renuncia daría a Menem un sexto nombramiento pronto.

${ }^{79}$ Todas estas maniobras son descritas en VERBITSKY (1993).

${ }^{80}$ El presidente Alberto Fernández convocó a un consejo de expertos, cuya mayoría propuso disminuir la mayoría (actualmente de dos tercios) necesaria para aprobar los pliegos del Procurador y Defensor General en el Senado. Un proyecto en ese sentido fue aprobado por el Senado y cuenta con dictamen favorable en las comisiones pertinentes de la Cámara de Diputados, donde aún tiene estado parlamentario. Además, algunos de los miembros del consejo de expertos han propuesto elevar el número de miembros de la Corte Suprema, lo que ha sido objeto de múltiples rumores políticos durante 2020 y 2021. Para una crítica del trabajo del consejo, véase GUIDI y NIETO (2020).
} 
En el régimen de la constitución de 1853, los jueces federales eran nombrados por el Presidente con acuerdo de la mayoría simple del Senado. ${ }^{81}$ Este sistema daba al partido gobernante una amplia discrecionalidad al momento de designar jueces, que luego quedaban prácticamente blindados en sus cargos (ya que sólo podían ser removidos a través del engorroso trámite de juicio político, que requería los dos tercios de cada Cámara del Congreso) ${ }^{82}$ Además, las facultades de superintendencia, administración y disciplina sobre el Poder Judicial estaban concentradas en la Corte Suprema (que, de nuevo, era percibida como indebidamente cercana al gobierno).

La Convención de 1994 creyó posible remediar estos problemas con la creación de un Consejo de la Magistratura, inspirado en los modelos europeos y que ya había comenzado a utilizarse en algunas provincias del país y en otros países de la región. ${ }^{83}$ En el nuevo articulado constitucional, el Consejo tendría a su cargo organizar concursos de oposición y antecedentes para elaborar ternas de las cuales el Poder Ejecutivo tendría que elegir a su candidato a ocupar el puesto, nuevamente con acuerdo del Senado. El Consejo también tendría a su cargo la facultad disciplinaria sobre los jueces y, en caso de faltas graves, formular una acusación ante un también novel Jurado de Enjuiciamiento con facultad para destituirlos. Por último, el Consejo tendría facultades de superintendencia y administración sobre el Poder Judicial.

Quiénes debían integrar un órgano tan novedoso en la arquitectura institucional argentina era una pregunta clave. Según el texto de la Constitución, "[e]l Consejo será integrado periódicamente de modo que se procure el equilibrio entre la representación de los órganos políticos resultantes de la elección popular, de los jueces de todas las instancias y de los abogados de la matrícula federal. Será integrado, asimismo, por otras personas del ámbito académico y científico, en el número y la forma que indique la ley ${ }^{{ }^{*}}{ }^{4}$

Ya en el seno de la asamblea, varios convencionales observaron que dejar el diseño del Consejo abierto a una futura ley orgánica -por más que esta debiese ser aprobada por mayoría especial $^{85}$ - dejaría su integración sujeta a las mayorías propias de cada coyuntura política. El líder del espacio progresista opositor Frente Grande, Carlos 'Chacho' Álvarez, observó que gracias a este defecto "... la Constitución se va a convertir en flexible". Algunos bloques minoritarios propusieron integraciones concretas, en general proponiendo integrar el Consejo

\footnotetext{
${ }^{81}$ Art. 86, inc., 5ํㅜ de la Constitución de 1853 (con la reforma de 1860).

${ }^{82}$ Id. art. 45 .

${ }^{83}$ La implementación de este tipo de consejo estuvo en boga en Latinoamérica en la década de 1990, promovidos por instituciones como el Banco Mundial. Véase por ejemplo DAKOLIAS (1997), pp. 12-13.

${ }^{84}$ Art. 114 Constitución Nacional argentina.

${ }^{85}$ Id.

${ }^{86}$ Convención Nacional Constituyente, 21 ${ }^{\underline{a}}$ Reunión - 3a Sesión Ordinaria (Continuación), $1^{\circ}$ de agosto de 1994, p. 2629. También el convencional por el partido derechista Unión de Centro Democrático, Iván Cullen, advirtió sobre la inconveniencia de no determinar la integración del Consejo en la propia Constitución (id. p. 2762).
} 
con una mayoría de jueces. ${ }^{87}$ Sin embargo, la entente del Pacto de Olivos desoyó estas advertencias, tal vez preocupados en alcanzar un texto posible.

La predicción de la minoría se cumplió con creces. En primer lugar, la primera ley de Consejo de la Magistratura tardaría cuatro años en promulgarse, precisamente por diferencias en torno a la manera en la que se integraría el Consejo, que finalmente quedó integrado por veinte miembros: cuatro diputados y cuatro senadores (en cada caso, dos por el bloque legislativo mayoritario, y uno por cada uno de los que le seguían), un representante del Poder Ejecutivo, cinco jueces (incluyendo al presidente de la Corte Suprema), cuatro abogados y dos académicos. ${ }^{88}$ Sin embargo, esta conformación no tardaría mucho en ser cuestionada. Entre 2004 y 2006, el gobierno de Néstor Kirchner argumentó que un Consejo de veinte miembros era 'elefantiásico', y auspició una reforma que redujo su integración a trece miembros (eliminando el legislador por el tercer bloque de cada Cámara y disminuyendo las representaciones de los restantes estamentos) ${ }^{89}$ La nueva integración, muchos denunciaron, tenía la particularidad de que otorgaba al oficialismo casi automáticamente cinco sobre trece miembros, lo que constituía una minoría de bloqueo contra las decisiones importantes del Consejo, que debían tomarse por dos tercios de los votos. Mucho tiempo después, esta reforma sería declarada inconstitucional en primera y segunda instancia, en un fallo que -a la fecha de presentación de este trabajo- se encuentra en estudio de la Corte Suprema de Justicia. ${ }^{90}$

La historia no terminaría allí. A pesar de haber promovido como senadora esta reforma, ya como presidenta Cristina Fernández de Kirchner impulsó una nueva modificación a la ley, que llevó su número a diecinueve. ${ }^{91}$ Esta vez no sólo cambiaría la cantidad de representantes asignados a cada estamento, sino también su modo de elección: académicos, abogados y jueces no serían ya electos por sus pares, sino en elecciones populares que se realizarían conjuntamente con las elecciones presidenciales cada cuatro años. ${ }^{92}$ Esta reforma fue inmediatamente cuestionada judicialmente, $\mathrm{y}$, ante la inminencia de las primeras elecciones en

\footnotetext{
${ }^{87}$ Véase por ejemplo la propuesta del convencional del Partido Socialista Guillermo Estevez Boero, en id. p. 2559 .

${ }^{88}$ En realidad, la ley 24.937 sancionada el 10 de diciembre de 1997 creaba un Consejo de 19 miembros, que incluía sólo un académico. La ley fue modificada antes de su entrada en vigencia por la ley 24.939, que, entre otras reformas, agregó el segundo académico.

${ }^{89}$ Para el debate en el Senado de esta reforma véase Cámara de Senadores, 42a Reunión, 2a Sesión Extraordinaria, 21 y 22 de diciembre de 2005, y para la calificación del Consejo como órgano "elefantiásico" véase en particular la intervención de la senadora Cristina Fernández de Kirchner, pág. 170 de la versión taquigráfica provisoria.

${ }^{90}$ Una historia de las sucesivas leyes que regularon el Consejo de la Magistratura y los diferentes fallos de los que han sido objeto puede leerse en DASSEN y GUIDI (2019).

${ }^{91}$ Ley 26.885, promulgada el 24 de mayo de 2013.

${ }^{92}$ Id. $\operatorname{art} 4^{\mathrm{o}}$.
} 
las que se elegirían consejeros, fue rápidamente declarada inconstitucional por la Corte Suprema en un fallo de seis votos contra uno $^{93}$.

Resulta particularmente interesante el voto disidente de Eugenio Raúl Zaffaroni, único ministro de la Corte que opinó que la reforma era constitucional. Zaffaroni había sido miembro de la Convención Constituyente por el Frente Grande y, en ese carácter, había denunciado precisamente que la regulación dejaba "sin decir nada sobre la proporción en que la integrarán [los nuevos órganos creados por la Constitución, como el Consejo] ni cómo será la elección”, y que "[c]ada vez que esto se ha hecho en la historia, apareció la lucha partidista disputándose la integración del consejo de la Magistratura" ${ }^{94}$. Ya como juez, recuperó su crítica, que recuerda a la de Calamandrei y que vale la pena citar in extenso:

La [...] reforma constitucional se caracterizó por perfilar instituciones sin acabar su estructura. En ocasiones se tiene la impresión de que simplemente marcó trazos gruesos, que se limitaron a esbozar órganos y competencias, muy lejos de la precisión necesaria para delinear una ingeniería institucional [...] En el propio seno de la Asamblea de Santa Fe se advirtió reiteradamente el riesgo que se corría con esta novedosa modalidad constitucional, puesto que es inevitable que la política coyuntural ocupe los huecos estructurales que deja abiertos el texto constitucional, con las soluciones que le dicte la circunstancia de poder de cada momento, no por corrupción y ni siquiera por razones contrarias a la ética, sino por la simple dinámica esencialmente competitiva de la actividad política, que irremisiblemente mueve a ocupar todos los espacios de poder que se le ofrecen en cada ocasión. ${ }^{95}$

Si bien Zaffaroni fue criticado por haber convalidado como juez lo que había criticado como constituyente, ${ }^{96}$ el mero hecho de haber tenido que decidir Rizzo le da la razón. La reforma de 2013, argumentó el juez, “... no se filtra por los resquicios del texto, sino que penetra por las enormes brechas que éste dejó abiertas a la ley infraconstitucional”. ${ }^{97}$ Ahora, dice Zaffaroni, “...podemos recriminarnos y hasta llorar...”, ${ }^{98}$ pero el daño está consumado. Sólo una reforma constitucional que estructure el texto de modo preciso evitará que el Consejo siga sujeto a rencillas políticas. ${ }^{99}$

\footnotetext{
${ }^{93}$ Rizzo, Jorge Gabriel, fallo del 18 de junio de 2013. El principal argumento del fallo es que el art. 114 de la Constitución habla de "representantes" de los jueces y abogados para integrar el Consejo, por lo que debían ser elegidos por ellos. Un análisis crítico de este fallo puede encontrarse en DASSEN y GUIDI (2019).

${ }^{94}$ Citado por el voto de Argibay y Zaffaroni en Rizzo con Estado Nacional (2013), cons. 7.

${ }^{95}$ Disidencia del juez Zaffaroni en Rizzo con Estado Nacional (2013), cons. $4^{\circ}$.

${ }^{96}$ Así por ejemplo se sugiere por el voto de los jueces Petracchi y Argibay en Rizzo con Estado Nacional (2013), cons. 8.

${ }^{97}$ Disidencia del juez Zaffaroni en Rizzo con Estado Nacional (2013), cons. 11.

${ }^{98}$ Id. cons. 12.

${ }^{99} I d$.
} 
La integración del Consejo sufrió todas las vicisitudes propias de este tipo de diseño institucional. La promulgación de la norma legal tardó casi media década, siendo igualmente reformada antes de su entrada en vigencia, para ser luego reformada dos veces más por el mismo gobierno buscando crecientes niveles de injerencia -reformas a la sazón declaradas inconstitucionales. Luego, tanto el ex presidente Mauricio Macri como el actual presidente Alberto Fernández anunciaron que buscarían su reforma nuevamente. ${ }^{100}$ Desde la sanción de la reforma constitucional hace más de 25 años, ningún presidente que haya terminado su mandato se ha privado de reformar la integración del Consejo o al menos intentarlo. Nada indica tampoco que esto vaya a dejar de pasar mientras la regulación constitucional del Consejo mantenga su laconismo.

La lección que el caso argentino nos entrega es de una vigencia inusitada para la discusión constitucional chilena. No sólo un número importante de convencionales constituyentes proponen la creación de un consejo análogo al argentino, sino que también el gobierno del presidente Piñera está promoviendo la creación de una entidad análoga en el Congreso. En esta última iniciativa, la experiencia del Consejo de la Magistratura argentina puede ser particularmente importante: la misma Corte Suprema chilena ha sugerido desde hace varios años la conveniencia de separar sus funciones jurisdiccionales de las administrativas y de gestión, entregando éstas a un órgano separado de ella. ${ }^{101}$ En su iniciativa, el Ejecutivo chileno parece incurrir en el mismo error que puede extraerse del caso argentino: entregar la composición y nombramiento de los integrantes del consejo a las mayorías legislativas. ${ }^{102}$ Más importante aún, nada permite inferir que no sea este el camino que finalmente adopte la Convención.

\subsection{Nunca: Chile 1925}

La inexistencia de tribunales administrativos en Chile suele ser considerada como una de las más grandes deudas del derecho público chileno. ${ }^{103}$ Esta deuda, además, se ve agravada por

\footnotetext{
${ }^{100}$ Sobre los planes del gobierno de Mauricio Macri puede consultarse Nicolás Misculin, Provectos para reformar Justicia de Argentina despiertan temores de injerencia entre jueces y fiscales, Reuters, 8 de diciembre de 2017 , https:/www.reuters.com/article/politica-argentina-justicia-idARL1N1O414L. El presidente Alberto Fernández, por su parte, solicitó a un Consejo Consultivo su opinión sobre la conveniencia de modificar la integración del Consejo de la Magistratura. Ante la respuesta afirmativa de dicho Consejo, anunció que enviaría un proyecto de ley al respecto al Congreso Nacional, aunque a la fecha de presentación de este escrito no lo ha hecho (véase, Palabras del Presidente Alberto Fernández en la Apertura del 139 período de sesiones ordinarias, del Honorable Congreso de la Nación Argentina, 1 de marzo de 2021, https://www.casarosada.gob.ar/informacion/discursos/47566-palabras-del-presidente-alberto-fernandez-en-laapertura-del-139-periodo-de-sesiones-ordinarias-del-honorable-congreso-de-la-nacion-argentina-caba). Para una crítica de las recomendaciones del Consejo Consultivo, véase GUIDI y NIETO (2020).

${ }^{101}$ Véase por ejemplo el punto VII del Acta №187-2014 de la Corte Suprema de fecha 26 de octubre de 2014, que contiene la Declaración XVII de las Jornadas de Reflexión de la Corte Suprema (pp. 8-9)

${ }^{102}$ Véase el proyecto de ley que propone la creación del Comisión Nacional de Nombramientos Judiciales, presentado al Congreso vía Mensaje №555-369 de fecha 16 de abril de 2021.
}

${ }^{103}$ Vid v.gr. PANTOJA (2001). 
el hecho de que durante décadas su creación fue una promesa constitucional, ya que el artículo 87 de la Constitución de 1925 establecía que:

Habrá Tribunales Administrativos, formados con miembros permanentes, para resolver las reclamaciones que se interpongan contra los actos o disposiciones arbitrarias de las autoridades políticas o administrativas y cuyo conocimiento no esté entregado a otros Tribunales por la Constitución o las leyes. Su organización y atribuciones son materia de ley.

Esta disposición constitucional puede explicarse por el contexto histórico-político que subyace a la discusión del texto de la Constitución de 1925. Uno de los principales propósitos buscados por el presidente Alessandri Palma con este proceso constituyente era la restauración de un régimen presidencial fuerte. ${ }^{104}$ Tanto él como los militares que lo apoyaban sostenían que esta era una buena alternativa ante los excesos políticos que trajo el parlamentarismo de facto que había imperado en el país por décadas. Como le señaló entre amenazas a los integrantes de la Comisión Constitucional el general Mariano Navarrete: “... el país está harto de la politiquería mezquina y quiere, de una vez por todas, tener un gobierno fuerte...”. ${ }^{105}$

De esta manera, la creación de tribunales administrativos puede explicarse como una forma de atenuar las críticas que los partidos políticos tenían respecto al proyecto presidencial de Alessandri y las Fuerzas Armadas. Esto explicaría las constantes alusiones sobre el rol que cumplirían estos tribunales en limitar la autoridad presidencial y servir además de freno a los posibles abusos de las instituciones administrativas. Por ejemplo, en las discusiones de las subcomisión a cargo de discutir el texto del artículo 87, el presidente Alessandri reconoció que muchas de estas reformas iban a significarle “...desprenderse de una serie de facultades...”, lo que se traduciría en que “...los Tribunales de que se trata estarían en condiciones de amparar a los empleados contra los posibles abusos de estos jefes [de oficinas o servicios públicos]. De otra manera, éstos quedarían sin control alguno". ${ }^{106}$ En la segunda y última sesión en que se discutió este tema, el presidente Alessandri nuevamente declaró que con la creación de los tribunales “...se propone limitar las facultades del Presidente". ${ }^{107}$

En idénticos términos argumentó quién actuó como secretario de la subcomisión durante esa segunda sesión, Fernando Alessandri Rodriguez. En su intervención, Alessandri Rodríguez -también hijo del presidente, su secretario privado y un destacado procesalista- se declaraba partidario de la creación de tribunales administrativos porque “...cada día se están aumentando las atribuciones del Estado y los asuntos que deben resolver las autoridades en única instancia...", de modo que "[l]o que se pretende es que los actos de las autoridades

\footnotetext{
${ }^{104}$ CORREA (2015), p. 272; DONOSO (1976), p. 272.

${ }^{105}$ Actas Oficiales, p. 455. Es importante tener presente que prácticamente toda la clase política apoyaba mantener el parlamentarismo de facto que habría precedido el quiebre institucional, como lo evidencian las declaraciones de fines de julio de 1925 en el periódico La Nación de los partidos Comunista y Conservador. DonOSO (1976), pp. 282-3.

${ }^{106}$ Actas, Sesión Vigésimo Octava de la Subcomisión de Reformas Constitucionales, 9/7/1925, p. 368.

${ }^{107}$ Actas, Sesión Trigésima Tercera de la Subcomisión de Reformas Constitucionales, 3/8/1925, p. 519
} 
administrativas que deban ejecutarse de acuerdo con las leyes y que no queden sometidas a la revisión de los tribunales ordinarios, puedan reclamarse a estos Tribunales Administrativos" ${ }^{108}$

El miedo de los partidos políticos hacía Alessandri y su partido político, por lo demás, no carecía de sustento: al retornar al mando del gobierno, Alessandri ejerció el liderazgo presidencial con poderes omnímodos y sin contrapeso parlamentario, al haber sido clausurado el Congreso por los militares luego del golpe de $1924 .{ }^{109}$ Los partidos políticos, cuya supremacía sobre el Ejecutivo había sido ejercida por décadas desde el Congreso, tenían sobradas razones para temer. Basta recordar la retórica incendiaria contra el Congreso que caracterizó la presidencia de Alessandri, sobre todo en sus recorridos por cuarteles militares. ${ }^{110}$

Es en este escenario que la subcomisión a cargo de la redacción del texto constitucional decide crear tribunales especializados e independientes del Poder Judicial. La elección por este modelo de control administrativo responde, por una parte, a una profunda concepción constitucional imperante en la época -y durante gran parte de la vigencia de la carta de 1925según la cual los tribunales pertinentes al Poder Judicial estaban vedados de revisar la actuación de los poderes políticos del Estado, por cuanto ello supondría una vulneración del principio de separación de poderes al entrometerse en las actuaciones del Ejecutivo. ${ }^{111}$ Así consta expresamente en las discusiones de la comisión a cargo de la redacción del artículo 87, al justificarse la necesidad de estos tribunales. ${ }^{12}$

Por otra parte, debe también recordarse la profunda desconfianza que generaba el Poder Judicial entre los militares que propiciaron el quiebre institucional en 1924 y que encargaron a Alessandri Palma la redacción de una nueva constitución. Esta desconfianza se explica en gran medida porque durante prácticamente toda la república parlamentaria (1891-1924), los partidos políticos influyeron a tal punto en los nombramientos judiciales que la composición

\footnotetext{
${ }^{108}$ Actas, Sesión Trigésima Tercera de la Subcomisión de Reformas Constitucionales, 3/8/1925, p. 519.

${ }^{109}$ EYZAGUIRRE (1979), p. 196.

${ }^{110}$ CORREA (2015), p.58

${ }^{111}$ Véase, por ejemplo, la referencia a los textos de José Victorino Lastarria en Junta de Gobierno (1982). Existían algunas posiciones minoritarias según las cuales las controversias entre los privados y el poder público debían ser entregadas a los tribunales ordinarios. Por ejemplo, HuneEus (1891).

Había finalmente quienes no compartían la necesidad de tribunales administrativos por causa de la separación de poderes, sino por razones pragmáticas. Así, Santiago VIVANCO señalaba que de entregarse todos los asuntos a los tribunales ordinarios, ello se traduciría en una 'verdadera denegación de justicia' ya que, ante la importante carga de trabajo de los tribunales en materias de derecho privado, difícilmente éstos difícilmente podrían prestar atención a materias administrativas que les eran del todo desconocidas. VIVANCO (1917), pp. 37-38.
}

${ }^{112}$ Actas, Sesión Trigésima Tercera de la Subcomisión de Reformas Constitucionales, 3/8/1925, pp. 518-9 (especialmente, intervenciones de Luis Barros Borgoño y Fernando Alessandri Rodríguez. Este último, ante una pregunta de uno de los comisionados, responde sobre la competencia de una tribunal común para conocer de un asunto contencioso-administrativo: “...no puede hacerlo porque ésta es y se declara incompetente para conocer en estas materias y el particular queda burlado, a menos que recurra a los gestores administrativos, para que ellos consigan con el Ministro respectivo...”p. 519. 
del poder judicial era un reflejo de los grupos dominantes al interior del Congreso. ${ }^{113}$ No es de extrañar entonces que se haya evitado entregar el control judicial del Ejecutivo a tribunales cuya complicidad con el Congreso era evidente.

El citado artículo 87 evidencia una clara ausencia de lineamientos para el legislador sobre la forma como debían diseñarse estos tribunales. Esta deficiente reglamentación sobre los contornos en que tenía que operar esta delegación legislativa puede explicarse, en primer lugar, por la casi nula atención que se le prestó al asunto. La creación de los tribunales administrativos fue objeto de debate sólo en parte de dos sesiones de trabajo de la subcomisión de redacción y hacia el final de su funcionamiento, acordándose su texto a sólo días del plebiscito llamado a ratificar la nueva Constitución. ${ }^{114}$

Más importante aún, tampoco parecería haber existido claridad respecto del rol que se buscaba asignar a estos tribunales. Como sostiene Rolando Pantoja, al defender la creación de estos tribunales el Presidente de la República “...no pudo bosquejar con nitidez [...] los perfiles esenciales que pondrían de manifiesto los tribunales administrativos, omitiendo un parecer que incluso contradecía el espíritu del precepto que esos instantes se analizaba”. ${ }^{115}$ Esta afirmación se fundamenta en que aparentemente el presidente Alessandri se habría contradicho en las dos sesiones que se discutió la creación de estos tribunales respecto del ámbito de su competencia. ${ }^{116}$ Por otro lado, Alessandri también exhortó a los integrantes de la subcomisión a rechazar la indicación presentada por Ezequías Allende que buscaba limitar la competencia de estos tribunales sólo a materias de empleo público, no obstante haber estado de acuerdo con esta idea en la sesión anterior. ${ }^{117}$

Ante el rechazo de esta indicación y atendida la premura por una nueva constitución (Alessandri concluía su mandato en sólo unos meses), es claro que la solución adoptada por los intervinientes fue aplazar aspectos sustantivos de la organización, competencia y funcionamiento de estos tribunales a instancias legislativas posteriores. Así lo evidencia la intervención de Luis Barros Borgoño, quien “... es de la opinión de dejar el artículo como está y que sea la ley a que el mismo artículo se refiere la que organice estos Tribunales, precisando sus atribuciones". ${ }^{118}$

El precio por esta delegación fue alto: a pesar de intentarse diversos esfuerzos legislativos, los tribunales administrativos nunca fueron creados. Estos tribunales -y la jurisdicción

\footnotetext{
${ }^{113}$ FAUNDEZ (2011). Justamente uno de los objetivos del movimiento militar que tuvo por propósito poner término a la república parlamentaria en 1924 fue depurar el poder judicial e impulsar una profunda reforma de éste.

${ }^{114}$ El texto del artículo 87 (originariamente 89) fue discutido durante parte de las 28va y 33ra sesión de las subcomisión, en los días 9 de julio y 3 agosto, en circunstancias que el plebiscito tuvo lugar el día 30 de agosto de 1925

${ }^{115}$ PANTOJA (1963), p.16 Señala también el autor que Alessandri Palma “...no tenía una idea clara del rol que representaban los Tribunales administrativos en el ámbito nacional”, aun a pesar de apoyar su creación (p. 17).

${ }^{116}$ Véase sesiones 28va y 33ra de las subcomisiones a cargo de la redacción del texto constitucional de julio y agosto de 1925.

${ }^{117}$ Actas, Sesión Trigésima Tercera de la Subcomisión de Reformas Constitucionales, 3/8/1925, pp. 518-20

${ }^{118}$ Actas, Sesión Trigésima Tercera de la Subcomisión de Reformas Constitucionales, 3/8/1925, p. 520.
} 
contencioso-administrativa en general- no pasaron de ser una categoría fantasmal durante la vigencia de toda la Constitución de $1925^{119} \mathrm{y}$, así, las distintas propuestas legislativas que buscaron abordar este tema, durante años recorrieron los pasillos legislativos en busca de un apoyo político que nunca existió realmente. ${ }^{120}$

Es precisamente esta falta de apoyo la que permite sugerir que difícilmente podría atribuirse al azar el fracaso en la creación de los tribunales administrativos. Durante la vigencia de esta norma constitucional, se presentaron cinco proyectos con propuestas que van desde aspectos fundamentales de la organización y composición de los tribunales administrativos así como su ubicación específica dentro de la arquitectura constitucional del Estado, hasta nimiedades como la localización de estos tribunales en el territorio nacional o su financiamiento. ${ }^{121}$ Tales diferencias produjeron disquisiciones y controversias en círculos académicos, todos sumamente legítimos, pero parecerían haber sido sin embargo utilizadas como una estrategia de dilación por parte de la clase política. Como señala Julio Faúndez, políticos provenientes de todos los partidos suscribieron con entusiasmo las más variadas controversias doctrinarias con el propósito de dilatar o entrabar la tramitación legislativa de estos proyectos en el Congreso. ${ }^{122}$ Por lo demás, esta actitud responde a una constante de la política constitucional de los siglos XIX y gran parte del XX: un esfuerzo compartido de la elite política de excluir a la judicatura de aspectos centrales de la gobernanza estatal. ${ }^{123}$ No debe sorprendernos entonces que incluso antes de su vigencia, los tribunales administrativos tuvieran jurados enemigos: así se desprende de la intervención del presidente del recién clausurado Senado Eliodoro Yañez, quien argumentaba durante los debates de la subcomisión “... que la creación de estos Tribunales Administrativos ... va a constituir un rodaje peligroso e inútil”. ${ }^{124}$

En consecuencia, durante toda la vigencia de la constitución de 1925 y frente a la imposibilidad de alcanzar un acuerdo legislativo sobre el diseño de los tribunales administrativos -sea como consecuencia de esfuerzos positivos de la clase política de impedirlo o por legítimas diferencias sobre el correcto diseño de estos tribunales-, la élite política desarrolló mecanismos alternativos para cumplir los fines fiscalizadores buscados con la creación de tales tribunales, como por ejemplo el fortalecimiento de la Contraloría General de la República. ${ }^{125}$

\footnotetext{
${ }^{119}$ PIERRY (2000), p. 97

${ }^{120}$ FUndación Facultad de Derecho de la Universidad de Chile (2001), p. 8.

${ }^{121}$ Ellos pueden ser consultados en Junta de Gobierno, Los Tribunales Contencioso Administrativos, Antecedentes para su Estudio, 277-390 (Armada de Chile, 1982).

${ }^{122}$ FAUNDEZ (2011), p. 164.

${ }^{123}$ FAUNDEZ (2010).

${ }^{124}$ Intervención de Eliodoro Yáñez, Actas, Sesión Vigésimo Octava de la Subcomisión de Reformas Constitucionales, 9/7/1925, p. 368.

${ }^{125}$ En esta línea, véase FAúNDEZ (2007).
} 
Nuevamente, ello responde a que la clase política compartía la idea que el control judicial sobre el proceso administrativo era innecesario y por lo tanto era preferible que las restricciones sobre el Ejecutivo provinieran del proceso político. ${ }^{126}$ Por lo tanto, este episodio chileno evidencia una derivación particular de decidir no decidir: una "dilación obstruccionista” que no es el resultado de discrepancias en torno al diseño de los tribunales y sus aspectos fundamentales, sino probablemente una estrategia para evitar precisamente su existencia.

\section{EXCUSAS, INTERESES Y PRINCIPIOS}

Los tres casos que hemos revisado proveen una constante. En todos los casos, la escasa regulación constitucional de instituciones judiciales fundamentales llevó a que estas se implementen tarde (como en los casos italiano y argentino), mal (como en el caso argentino y en los primeros intentos de regulación de la Corte Constitucional por parte de la Democracia Cristiana italiana) o, sencillamente, nunca (como con los tribunales administrativos chilenos). Con las limitaciones propias de un estudio comparativo con pocos casos, nos atreveremos a extraer algunas lecciones preliminares de estos distintos procesos.

Si bien hemos mostrado que la escasa regulación constitucional desembocó, en los tres casos, en demoras o defectos en la implementación de las instituciones analizadas, hemos dicho poco acerca de cuáles son los mecanismos que pueden haber estado en juego. En este capítulo nos proponemos leer los tres casos a la luz de tres posibles mecanismos que explican cómo la escasa regulación puede conllevar estos resultados. Los llamaremos la provisión de excusas, la falta de coordinación y el desacuerdo de principios. En el primer caso, los legisladores aprovechan la escasa regulación constitucional y sus múltiples interpretaciones como una excusa para no implementar aquello que no desean que exista. En el segundo caso, por el contrario, los legisladores buenamente pueden querer implementar la institución esbozada en la constitución, pero carecen de una guía común que les permita hacerlo sin ceder más de lo que estiman imprescindible en las inevitables negociaciones. El tercer caso es ligeramente diferente: no es que la falta de regulación constitucional cause directamente los problemas en la implementación, sino que ambos son causados por un desacuerdo de principios más o menos fundamental. A cada uno de estos mecanismos corresponde una posible objeción a nuestro argumento, a las que respondemos también a continuación.

\subsection{Provisión de excusas}

Una regulación constitucional demasiado amplia entrega una excusa perfecta a futuros legisladores para no implementar aquello cuya existencia desean evitar. Y es de esperar que no quieran hacerlo: los entes creados por las constituciones restringen, casi por definición, competencias que eran previamente ejercidas por otros órganos. Además, al insertarse en el esquema institucional de frenos y contrapesos, amenazan con controlar o restringir el ejercicio del poder de los órganos existentes. En estas circunstancias, no es de extrañar que los órganos encargados de su creación e implementación sean refractarios a hacerlo o que intenten hacerlo

\footnotetext{
${ }^{126}$ FAUNDEZ (2011), p. 164.
} 
de tal modo que sus competencias queden disminuidas o limitadas. Como dijo Piero Calamandrei a propósito de la tarea del Parlamento italiano completando el diseño de la Corte Constitucional, es como poner a los lobos a fabricar los candados del corral de las ovejas ${ }^{127}$ (o, nuevamente, como Bertoldo buscando su árbol).

En estas circunstancias, no es de extrañar que los poderes constituidos 'arrastren los pies' al momento de implementar las promesas institucionales del constituyente. De hecho, vemos esta dinámica en los tres casos que estudiamos en el capítulo anterior. En Argentina, el Congreso dominado por el partido del presidente tardó cuatro años en crear el Consejo de la Magistratura que les quitaría a ambos el poder sobre el nombramiento y remoción de todos los jueces federales del país. En Italia, el Parlamento de mayoría democristiana tardó cinco años en crear la Corte Constitucional que podría invalidar las leyes dictadas por él mismo (y otros tres en nombrar a los jueces correspondientes). En Chile, la clase política derechamente nunca creó los tribunales administrativos que tendrían por propósito precisamente controlar el mayor premio al que sus coaliciones podrían aspirar a conquistar: el Ejecutivo. En los primeros dos casos, el grueso de las negociaciones que tomaron años giraron precisamente alrededor de cuestiones centrales de composición y nombramiento de los integrantes de las instituciones a crearse, que podrían haber estado resueltas en el texto constitucional. En el tercero, un texto constitucional más preciso podría haber evitado discusiones inconducentes y facilitar los ocasionales esfuerzos reformistas.

Esta dinámica es tan común que Jodi Finkel ha sugerido que las reformas judiciales, no obstante estar prometidas o promulgadas legislativamente, son implementadas recién cuando el gobierno con la capacidad real de hacerlo percibe que su poder peligra y, así, se quedará con los méritos de la reforma judicial mientras su sucesor será el que pagará los costos de un mayor control. ${ }^{128}$ Esta dinámica también se dio, con matices, en los tres casos que hemos descrito. En Argentina, la mayoría oficialista del Congreso aprobó la creación del Consejo de la Magistratura recién después de perder las elecciones de medio término de 1997 que sepultarían las esperanzas del presidente Menem de ser nuevamente reelecto. ${ }^{129}$ En Italia, la Democracia Cristiana retrasó la creación de la Corte Constitucional mientras tuvo mayoría parlamentaria y recién avanzó con ella cuando creyó que podría controlarla por más tiempo de lo que tenía asegurado su control del Parlamento. ${ }^{130}$ En Chile, si bien parecía haber consenso transversal en la clase política en boicotear la creación de los tribunales administrativos, hay episodios que también sugieren lo descrito por Finkel. Por ejemplo, el gobierno del presidente Carlos Ibáñez del Campo presentó un proyecto de tribunales administrativos a menos de dos meses de realizarse las elecciones presidenciales en las que resultó electo Jorge Alessandri Rodríguez. ${ }^{131}$

\footnotetext{
${ }^{127}$ Calamandrei (1966), p. 223

${ }^{128}$ FINKEL (2008).

${ }^{129}$ Este ejemplo es de la propia FinKEL (2008), pp. 57-58.

${ }^{130}$ Mary VOLCANSEK explícitamente encuadra la sanción e implementación de la Corte Constitucional italiana en la dinámica de aseguramiento propuesta por FINKEL, véase VOLCANSEK (2010).
}

${ }^{131}$ Véase el 'Proyecto Zúñiga’ de fecha 21 de julio de 1958 en Junta de Gobierno (1982). 
Este fenómeno invita a una objeción a nuestro argumento: si la implementación de las reformas judiciales depende de la pérdida del poder del partido gobernante, tal vez la frugalidad de la regulación sea inocente de nuestra acusación (y, simétricamente, una regulación más específica sea impotente para sortearla). Una versión de esta objeción podría ir más lejos y afirmar que las excusas son irrelevantes para la acción política real y que, si los políticos renuentes a implementar las reformas no tienen la excusa de la parquedad constitucional, rápidamente encontrarán otras.

Cabe reconocer, desde ya, que ciertamente la densidad de la regulación no es el único factor que condiciona el éxito o el fracaso de las instituciones creadas por la constitución. Pero aunque tal vez no pueda evitar que los futuros legisladores se inclinen hacia el 'obstruccionismo de mayoría', sí puede privarlo de excusas para hacerlo. No es lo mismo que un Congreso se oponga a un mandato constitucional por mero capricho que por desavenencias que pueden ser presentadas ante la ciudadanía como legítimos desacuerdos de carácter técnico. Como recuerda Faúndez para el caso chileno, un texto vago permite la proliferación de discusiones y doctrinas de lo más variadas con tal de retrasar la implementación de lo que no se desea implementar. ${ }^{132}$ Además, un texto preciso facilita a la oposición y a la sociedad civil ejercer presión por una implementación concreta en lugar de ponerlos en la incómoda posición de abogar por un diseño institucional propio o de esperar un consenso improbable en la dirigencia política. ${ }^{133}$

\subsection{Falta de coordinación}

Aún si pensamos en actores políticos con intenciones sinceras de implementar las reformas prometidas en la Constitución, la indeterminación constitucional puede llevar a una disputa política acerca de a quién le corresponde qué. Todos los actores con poder de influencia pueden acordar en que es mejor que la institución en cuestión exista, pero nadie estará inmediatamente dispuesto a relegar los lugares que pueda obtener en ella. No es difícil ver esta dinámica en juego en el caso italiano y, especialmente, en el argentino. Como afirmó el juez Zaffaroni, "la simple dinámica esencialmente competitiva de la actividad política [...] irremisiblemente mueve a ocupar todos los espacios de poder que se le ofrecen en cada ocasión”. ${ }^{134}$

Enojarse con este proceso es como enojarse con la ley de gravedad. El constituyente no debería esperar de los futuros legisladores actos de renuncia voluntaria al poder sino que

\footnotetext{
${ }^{132}$ Véase FAÚNDEZ (2011), p. 164.

${ }^{133}$ La cuestión de la especificidad de las normas y sus consecuencias en su legitimidad y cumplimiento ha sido extensamente tratada en la teoría de las relaciones internacionales. Si bien este es un campo diferente y no necesariamente sus conclusiones pueden trasladarse al diseño constitucional sin más, es interesante la observación de FRANCK (1991): “cuando más determinado es un estándar, más difícil es justificar su falta de cumplimiento” (pág. 54). Para un desarrollo mayor de este argumento, véase el libro citado de FRANCK (págs. 50-66) y LEGRO (1997).
}

${ }^{134}$ Rizzo con Estado Nacional (2013), cons. $4^{\underline{0}}$. 
debería, como propusieron los autores de El Federalista, "economizar en virtud". ${ }^{135}$ En estas circunstancias, el constituyente puede anticiparse a los enormes costos de negociación que implicaría la implementación de estos órganos y directamente decidir cuestiones centrales por sí mismo. Esto puede que suponga una pérdida menor para tal o cual partido, pero que será compensado por haber logrado evitar mantener la cuestión del diseño institucional perpetuamente abierta.

Además, los constituyentes suelen poseer la ventaja de no poder prever con aceptable precisión quién ocupará el poder pocos años después de su trabajo. Los legisladores, en cambio, siempre se encuentran legislando para una composición realmente existente del Congreso, sin poder nunca asegurarse contra los desmanes de una futura mayoría. ${ }^{136}$ Como afirmó el juez de la Corte Suprema estadounidense Louis Brandeis en otro contexto, en casos como este no es tan importante que estas cuestiones se zanjen de modo correcto, sino simplemente que se zanjen de algún modo. ${ }^{137}$

Se podrá objetar que existen herramientas menos intrusivas mediante las cuales el constituyente podrá incentivar al legislador a romper la inercia institucional, como por ejemplo el establecimiento de plazos estrictos con reglas por defecto ('default rules') en caso de incumplimiento. Estos mecanismos, además, podrían proveer un 'punto focal' que ayude a resolver los problemas de coordinación de la política ordinaria. ${ }^{138}$ Sin duda, estas herramientas pueden ser útiles en ocasiones. Sin ir más lejos, la complejísima transición constitucional sudafricana fue posible, en parte, gracias a un acuerdo constitucional interino que sería luego reemplazado por la constitución definitiva. ${ }^{139}$

Sin embargo, no debemos sobreestimar su potencia ni subestimar su dificultad. En primer lugar, una regla por defecto tal vez puede proveer un remedio a la inercia legislativa, pero no a las sucesivas capturas de las que la institución puede ser objeto por sucesivas mayorías circunstanciales. ${ }^{140}$ Piénsese en el caso argentino estudiado en este artículo: la constitución impuso una cláusula transitoria obligando al Congreso a sancionar la ley del Consejo de la Magistratura en el plazo de un año, so pena de que no podrían nombrarse más jueces a partir

\footnotetext{
${ }^{135}$ Según la lectura que hace ACKERMAN (1984).

${ }^{136}$ Jon Elster sugiere que si "todas las instituciones estuvieran al alcance de la mano todo el tiempo, quienes están en el poder estarán tentados de aprovechar sus cargos para propósitos privados, y aquellos que están fuera del poder dudarán antes de formar parte en proyectos que toman tiempo en rendir frutos. Además, si nada nunca podrá darse por resuelto, habrá grandes pérdidas producto de negociaciones y faccionalismos infructuosos” (Introduction en HOLMES (1988), p. 9).

${ }^{137}$ Burnet v. Coronado Oil \& Gas Co. (1932) ("Stare decisis is usually the wise policy, because, in most matters, it is more important that the applicable rule of law be settled than that it be settled right").

${ }^{138}$ La propia Dixon estudia esta posibilidad en DIXON (2019), pp. 179-182.

${ }^{139}$ Véase por ejemplo ACKERMAN (2019), cap. 3.

${ }^{140}$ Como por ejemplo en los casos italiano y argentino estudiados en este trabajo.
} 
de la expiración de tal plazo. ${ }^{141}$ La ley del Consejo tardó dos años adicionales a este plazo y, en el interregno, hubo una enorme puja política en la que el presidente constantemente amenazó con nombrar jueces por decreto. ${ }^{142} \mathrm{El}$ saldo de esta cláusula transitoria es entonces ambiguo: tal vez haya servido para apurar la sanción de la ley, ${ }^{13}$ pero no impidió sus sucesivas manipulaciones.

En segundo lugar, ciertas reglas por defecto pueden parecer atractivas en teoría pero serán luego difíciles de implementar. Esto ocurre en particular cuando se prevé una regla especialmente disruptiva con el fin de que sea disuasiva, con el efecto de que termine siendo inaceptable para las instituciones existentes. Piénsese, por ejemplo, en la regla por defecto en la constitución italiana, que establecía que hasta tanto la Corte Constitucional fuera creada los tribunales ordinarios ejercerían el control de constitucionalidad. El resultado no fue el esperado (presionar al legislador para crear la Corte para evitar que cualquier juez pudiera invalidar sus actos) sino el contrario (ya que los jueces ordinarios decidieron abdicar en la práctica de ejercer dicha atribución). ${ }^{144}$ Algo similar ocurrió en el caso chileno estudiado más arriba: ante la ausencia de los tribunales administrativos, los tribunales ordinarios se negaron a conocer los litigios contra la Administración al oponer su incompetencia sobre dichos asuntos, ${ }^{145}$ al punto que cuando excepcionalmente un tribunal aceptó la competencia para hacerlo se desató un conflicto político en el que incluso intervino el Presidente de la República. ${ }^{146}$

Por último, en ocasiones diseñar una regla constitucional por defecto para suplir la futura inacción legislativa puede demandar un esfuerzo tan grande como el de redactar una norma definitiva. En efecto, si la norma está destinada a perdurar mientras no sea modificada por los legisladores, aquellos grupos que se beneficien del default tendrán incentivos para mantener la inercia constitucional. Si esto es así, los constituyentes deberán tener cuidado de no repartir poderes de veto de modo demasiado pródigo. Si los constituyentes no logran hacer esto, tendrán en todo caso motivos para creer que la regla provisional se transformará en una regla definitiva, con lo que volvemos al punto de partida.

\footnotetext{
${ }^{141}$ La cláusula transitoria decimotercera disponía que ‘[a] partir de los trescientos sesenta días de la vigencia de esta reforma los magistrados inferiores solamente podrán ser designados por el procedimiento previsto en la presente Constitución. Hasta tanto se aplicará el sistema vigente con anterioridad."

${ }^{142}$ Véase por ejemplo BIELSA y GRAÑA (1996), pp. 561-563 (narrando contemporáneamente parte de la disputa política alrededor de la ley del Consejo).

${ }^{143}$ Otras leyes ordenadas por la constitución sin una previsión similar tardaron más de una década en sancionarse, como por ejemplo la ley de control de los decretos presidenciales, que se sancionó recién en 2006.

${ }^{144}$ Véase supra Parte II.1.

${ }^{145} \mathrm{Al}$ existir un artículo constitucional que declaraba la existencia de tribunales administrativos, la justicia ordinaria sistemáticamente se declaró incompetente para conocer contiendas contencioso-administrativas fundado en que los artículos cuarto tanto del Código Orgánico de Tribunales de 1943 como de su antecesora Ley de Organización y Atribuciones de los Tribunales de Chile de 1875 prohibían al Poder Judicial mezclarse en las atribuciones de otros poderes públicos y ejercer otras funciones que expresamente les estuvieran atribuidas.
}

${ }^{146}$ Socotransco con Fisco (1964), p. 7. 


\subsection{El desacuerdo de principios}

Finalmente, puede que los desacuerdos no surjan de competencia por espacios de poder, sino simplemente por diferencias de opiniones en temas de principios. Si este es el caso, ya no estaremos hablando (como en los casos anteriores) de que la falta de regulación constitucional sea la que causa los problemas de diseño legislativo, sino que en todo caso será el desacuerdo de principios el que causa tanto la regulación constitucional escasa como los problemas de un posterior diseño. Sin embargo, cabe considerar a la primera como "causa" de los segundos en el sentido de que frecuentemente sería más fácil y conveniente zanjar dichos desacuerdos en la etapa de diseño constitucional que en una etapa legislativa posterior.

Contra el caso de desacuerdo de principios cabe una objeción entendible a nuestra recomendación de alcanzar acuerdos detallados en la redacción de la constitución. Como desarrollamos más arriba, en aspectos centrales de la 'constitución de la conversación' las cláusulas abiertas permiten a diferentes grupos coexistir en la comunidad política reclamando para sí el amparo de la constitución. Constitucionalizar con especificidad la relación entre el Estado y la religión, por ejemplo, podría sofocar posiciones políticas legítimas, lo que a la larga podría socavar la legitimidad de la propia Constitución. ${ }^{177}$ En cambio, en materias propias de la constitución de lo zanjado, decíamos, la precisión es deseable, porque impide que haya disputas allí donde no debe haberlas. Sin embargo, al diseño institucional también subyacen cuestiones de principios. ${ }^{18}$ Piénsese, por ejemplo, en cómo distintos diseños institucionales traslucen diferentes visiones sobre el grado deseable de independencia judicial, o de subordinación de la voluntad mayoritaria a los derechos individuales. Por poner un ejemplo de nuestros casos de estudio, puede citarse la inflamada retórica democrática que acompañó la reforma al Consejo de la Magistratura argentino de 2013 para permitir la elección popular de sus miembros: el gobierno entonces logró que la discusión girara alrededor de la "democratización de la Justicia." "' Zanjar cuestiones de esta densidad ideológica en la Constitución podría precluir debates democráticos futuros.

Sobre esto igualmente caben algunas observaciones. En primer lugar, aun cuando se invoquen argumentos ideológicos, no es para nada obvio que ellos sean realmente lo que causa el atasco constitucional. Como notan Dixon y Ginsburg, las causas que llevan a los constituyentes a 'decidir no decidir' suelen ser asuntos más prosaicos como la carga de trabajo de los constituyentes y la gran cantidad de asuntos a definir. Antes de diagnosticar un desacuerdo como 'ideológico', cabe examinar si la posibilidad de llegar a 'consensos superpuestos' ha sido extremada.

\footnotetext{
${ }^{147}$ Supra parte II.1.

${ }^{148}$ Sobre cómo el diseño de instituciones judiciales puede traslucir principios constitucionales aún en la ausencia de una constitución escrita como la británica, puede consultarse DELANEY (2016).

${ }^{19}$ Véase por ejemplo el discurso de la presidenta Cristina Fernández al presentar los proyectos, Plan para la democratización de la Justicia: Palabras de la Presidenta, 9 de abril de 2013, en https://www.casarosada.gob.ar/informacion/archivo/26421-plan-para-la-democratizacion-de-la-justiciapalabrasde-al-presidenta
} 
Sin embargo, aun si concluyéramos que lo que impide a los constituyentes llegar a un acuerdo sobre la regulación de las instituciones judiciales son diferencias ideológicas de fondo, seguirá siendo deseable que extremen los esfuerzos para resolverlas en lugar de delegarla a la próxima legislatura (¡donde de todos modos tendrán que ser resueltas!). Como observa la propia Dixon, la 'política constitucional' suele estar orientada por un espíritu público que permita acuerdos que comúnmente no está presente en la 'política ordinaria'. ${ }^{150}$ Una vez concluido este proceso, la vorágine de la discusión política cotidiana y las múltiples demandas ciudadanas que pesan sobre los legisladores hacen esperable que ellos ubiquen el diseño institucional en un plano secundario. La experiencia chilena es reveladora: la inacción legislativa ha llevado a que la regulación una multiplicidad de cuestiones judiciales de gran importancia deban ser suplidas por auto acordados de la Corte Suprema, abarcando desde la tramitación de la acción de protección hasta las suplencias en los tribunales superiores de justicia. ${ }^{1.51}$

Por último, la ventaja de la constituyente por sobre el legislador ordinario no es sólo psicológica. La asamblea constituyente se encuentra en la posición privilegiada de tener una visión de sistema al trazar la arquitectura constitucional, pensando las instituciones como un todo y administrando balances de poder entre ellas. Así, diseñar instituciones judiciales en instancias legislativas supone aceptar una serie de restricciones y constreñimientos institucionales impuestos por los restantes engranajes de la 'sala de máquinas' a los que no necesariamente están sujetos quienes diseñan estas instituciones en procesos constituyentes. Además de este menor grado de libertad, en la política legislativa son frecuentes las negociaciones entre temas que no están vinculados entre sí. ${ }^{152}$ No es difícil ver por qué querríamos que la cantidad de miembros de una corte constitucional o un consejo de la judicatura no estén en la misma mesa de negociación que una obra de infraestructura en tal o cual distrito.

\section{CONCLUSIÓN}

En el capítulo anterior hemos mostrado los mecanismos que llevan a que la escueta regulación constitucional sea un factor en el fracaso de las instituciones judiciales creadas con la ambición de poner un límite a los poderes constituidos existentes. Ciertamente los retrasos o deficiencias descritos en los capítulos anteriores no se deben sólo a la mala regulación constitucional, pero sí se deben en parte importante a ella. Prestar atención a este factor, entonces, no resuelve por sí mismo la cuestión, pero sí es indispensable para hacerlo.

\footnotetext{
${ }^{150}$ DIXON (2019), p. 176 (“[L]os procesos constitucionales, como nota Bruce Ackerman, frecuentemente tienen lugar en un "momento" de elevada deliberación pública y compromiso con el cambio, y por lo tanto apertura a los acuerdos políticos. A medida que este momento llega a su fin, y las dinámicas políticas ordinarias se imponen, puede ser mucho más difícil para las élites políticas obtener el grado de apoyo mayoritario para el cambio necesario").

${ }^{151}$ SIERRA (2020).

${ }^{152}$ Sobre la práctica de las leyes misceláneas (en inglés, logrolling), véase en general GiMÉNEZ (2008).
} 
Delimitar qué elementos deben ser resueltos a nivel constitucional y cuáles no es una cuestión compleja que no podemos responder con precisión en este ensayo exploratorio. Por supuesto que la reglamentación excesiva en el diseño constitucional es inconveniente y, de hecho, hay materias judiciales en las cuales la delegación parecería ser conveniente. Los mismos Dixon y Ginsburg mencionan casos en Australia y los Estados Unidos sobre cuestiones judiciales en las que se consideró preferible recurrir a la delegación: la determinación y competencias de tribunales inferiores, atendiendo a la organización federal de ambos países. ${ }^{153}$

Para concluir, deseamos especular sobre ciertas cuestiones judiciales específicas en las que la delegación no resulta conveniente. En ello, somos plenamente conscientes de las limitaciones de nuestro estudio: ciertamente necesitamos un número mayor de casos de estudio para llegar a generalizaciones más específicas. Pero debido a la urgencia de la tarea de la Convención, nos atrevemos a aventurar que los aspectos centrales de la composición, sistema de nombramiento y remoción de los integrantes de las instituciones judiciales no deben ser dejadas a la futura reglamentación legislativa.

Dejar estos elementos abiertos a la reglamentación futura no es poco frecuente. En dos de los tres casos que hemos revisado (el italiano y el argentino) el nombramiento de sus integrantes estuvo en el centro de la disputa política, a pesar de que el constituyente hizo algún tímido intento por precisarlo, que se demostró insuficiente. Existen otros casos no tratados en este ensayo que parecen apoyar la recomendación preliminar de que la falta de especificación de estos elementos en el texto constitucional trae inercia e inestabilidad en la etapa de implementación: puede pensarse en la Corte Suprema y del Ministerio Público en la Argentina, ${ }^{154}$ o el Consejo General del Poder Judicial en España. ${ }^{155}$

Sin ir más lejos, ni siquiera la constitución más antigua del mundo está exenta de estas vicisitudes. Sanford Levinson utilizaba precisamente el número de los miembros de la Corte Suprema norteamericana como un caso atípico en el que la regla de que son nueve se mantiene como una tradición inconmovible a pesar de no estar en el texto escrito de la constitución. ${ }^{156}$ Escribía en 2012 que el fracaso de Franklin Delano Roosevelt en ampliar la Corte Suprema tal mostraba que el número de nueve jueces se había vuelto parte de la "Constitución no escrita” y que eso explicaba que nadie había siquiera sugerido que Barack Obama debía ampliar su número para sobreponerse a una Corte hostil. ${ }^{1.57}$ Nueve años después, sin embargo, un nuevo gobierno puso nuevamente en cuestión el número de miembros de una Corte que

\footnotetext{
${ }^{153}$ DiXON y GinsBurg (2011a), p. 646. Véase artículo 71 de la constitución de Australia y artículo 3 sección 1 de la constitución de los Estados Unidos.

${ }^{154}$ Véase supra nota 80.

${ }^{155}$ Sobre la modificación legislativa realizada en 1985 que permitió mayor control político sobre el Consejo, y sobre otras discusiones persistentes relacionadas con su integración, véase SERRA CRISTÓBAL (2013).

${ }^{156}$ LEVINSON (2012), p. 252. Claro que no es el único que hacía este argumento. Véase por ejemplo los trabajos citados en EPPS y SITARAMAN (2019).

${ }^{157}$ LEVINSON (2012), p. 252 (agregando que "[e]n la medida que uno crea que mantener a la Corte Suprema como un cuerpo de nueve miembros es algo bueno, tal vez es una debilidad de la Constitución de 1987 no haber especificado el tamaño de la Corte”).
} 
le resulta hostil, con el apoyo de un número importante de académicos. ${ }^{158}$ Puede irse algo más atrás: el gobierno anterior había forzado también las reglas no escritas de nombramiento de jueces supremos para asegurarse el control sobre la Corte. ${ }^{159}$ Independientemente de lo que uno piense de la sabiduría de cada una de estas decisiones, es evidente que la falta de reglas constitucionales sobre estos asuntos trajo serios inconvenientes.

La Convención está frente a un desafío enorme en muchos frentes, en una sociedad conflictuada pero esperanzada. Ante la épica de su tarea de forjar un nuevo pacto social, asuntos prosaicos como la composición de órganos judiciales y los mecanismos de nombramiento de sus integrantes corren el riesgo de ser postergados al fondo de la discusión. Esto sería un error: ante la ubicuidad del fenómeno de la "juristocracia”, los nombramientos judiciales de hoy bien podrían ser los derechos fundamentales de mañana. Evitar prestarle atención a este asunto es como decirse que se empezará a ejercitar el próximo lunes: tal vez entendible y reconfortante, pero en definitiva engañoso.

\footnotetext{
${ }^{158}$ Sobre la comisión creada por el presidente Biden para estudiar el funcionamiento de la Corte Suprema, incluyendo su número de miembros, puede consultarse Evan Osnos, Biden inherits F.D.R.'s Supreme Court problem, New Yorker, 18 de abril de 2021, https:/www.newyorker.com/magazine/2021/04/26/biden-inheritsfdrs-supreme-court-problem Una revisión del debate académico reciente acerca de la cuestión puede consultarse en EPPS y SiTARAMAN (2019), pp. 175-177, quienes además proponen un sistema de asignación de miembros por sorteo entre los jueces de las cortes de circuito (id. págs. 181 y ss.).

${ }^{159}$ Donald Trump nombró a tres miembros de la Corte Suprema, y dos de ellos de modo cuestionado por la oposición demócrata. Para nombrar al primero de ellos, Neil Gorsuch, debió eliminar la tradición del "filibuster" (es decir, la facultad de cada senador de hablar por tiempo ilimitado, bloqueando así la facultad de votar del cuerpo) en las sesiones de nombramiento de jueces. Para nombrar a Amy Coney Barrett, la mayoría republicana del Senado debió apartarse del precedente recientemente creado por ella misma para bloquear el nombramiento de Merrick Garland por parte de Barack Obama, que consistía en no aprobar nombramientos realizados por jueces en el último año de su gobierno. Sobre el primer caso, véase Matt Flegenheimer, "Senate Republicans Deploy 'Nuclear Option' to Clear Path for Gorsuch, New York Times, 6 de abril de 2017. Sobre el segundo, Nicholas Fandos, "Senate Confirms Barrett, Delivering for Trump and Reshaping the Court, New York Times, 26 de octubre de 2020.
} 


\section{BIBLIOGRAFÍA CITADA}

ACKerman, Bruce (1984). "Discovering the Constitution”, 93 Yale Law Journal 1013, 1031 (1984).

Ackerman, Bruce (2014). We The People III The Civil Rights Revolution 1, Harvard University Press.

ACKerman, Bruce (2019). Revolutionary Constitutions. Charismatic Leadership and the Rule of Law, Harvard University Press.

Aldunate, Eduardo (2016). "Reflexiones en torno al rol de la Corte Suprema en el gobierno judicial” en Reforma al PoderJudicial: GobiernoJudicial, Corte Suprema y Gestión.

Alfonsín, Raúl (1996). Democracia y Consenso, Corregidor, Buenos Aires.

BALKin, Jack (2001). "Bush v. Gore and the Boundary between Law and Politics” 110 (8) Yale Law Journal 1407.

Barsotti, Vittoria, Carozza, Paolo G., Cartabia, Marta y Simoncini, Andrea (2015). Italian Constitutional Justice in Context, Oxford University Press.

Bielsa, Rafael y Graña, Eduardo (1996). Justicia y Estado. A propósito del Consejo de la Magistratura, Ciudad Argentina.

CADEM (2021a). Encuesta Plaza Pública Cadem Estudio №384 (Mayo 2021) https:/plazapublica.cl/wp-content/uploads/2021/05/Track-PP-384-Mavo-S3-VF.pdf

CAdem (2021 B). Véase por ejemplo, Encuesta Cadem Plaza Pública, Primera semana de Junio - Estudio No386. Disponible en:, pág. 23 https://www.cadem.cl/wpcontent/uploads/2021/06/Track-PP-386-Junio-S1.pdf (ubicando a la Convención constituyente como la institución estatal con mayor confianza ciudadana del país).

Calamandrei, Piero (1955). "La Costituzione e le leggi per attuarla”, en Achille Battaglia y otros, Dieci anni dopo 1945-1955. Saggi sulla vita democratica italiana, Editori Laterza, Bari.

Calamandrei, Piero (1966). Scritti e discorsi politici, La Nuova Italia, 1966, Tomo I.

Chemerinsky, Erwin (2000-2001). "Bush v. Gore Was Not Justiciable" 76 Notre Dame Law Review 1093.

Correa, Sofía (2015). "Los Procesos Constituyentes en la Historia de Chile: Lecciones para el Presente”, Estudios Públicos 137 (verano 2015), pp. 43-85.

Couso, Javier y Hilbink, Lisa (2011). "From Quietism to Incipient Activism The Institutional and Ideological Roots of Rights Adjudication in Chile”, en Gretchen Helmke \& Julio Ríos-Figueroa, Courts in Latin America (Cambridge University Press).

Dakolias, María (1997). El sector judicial en América Latina y el Caribe. Elementos de reforma, Documento técnico del Banco Mundial N. 319S, Washington D.C. 
Dassen, Nicolás y GuIDI, Sebastián (2019) "Comentario al artículo 114", en Roberto Gargarella y Sebastián Guidi (dirs.), Constitución Nacional Argentina Comentada, Thomson Reuters, Buenos Aires.

DELANEY, Erin (2016). "Searching for constitutional meaning in institutional design: The debate over judicial appointments in the United Kingdom”, 14 International Journal of Constitutional Law 752 (2016).

DixOn, Rosalind (2015). "Constitutional drafting and distrust", 13 International Journal of Constitutional Law 819, 825.

Dixon, Rosalind (2019). "Constitutional design deferred”, en David Landau y Hanna Lerner (eds.), Comparative Constitution Making, Edgar Elgar.

Dixon, Rosalind y Ginsburg, Tom (2011a). "Deciding not to decide: Deferral in constitutional design”, 9 International Journal of Constitutional Law 636 (2011).

Dixon, Rosalind y Ginsburg, Tom (2011b). "The South African Constitutional Court and Socio-Economic Rights as "Insurance Swaps", 4 Const. Ct. Rev. 1 (2011).

Donoso, Crescente (1976). Notas sobre el Origen, Acatamiento y Desgaste del Régimen Presidencial 1925-1973.

EpPS, Daniel y Sitaraman, Ganesh (2019). "How to Save the Supreme Court", 129 Yale Law Journal 148, 176 n. 111 (2019)

Eyzaguirre, Jaime (1979). Historia de las Instituciones Políticas y Sociales de Chile, Editorial Universitaria.

FAÚNDEZ, Julio (2007), "The Fragile Foundation of Administrative Legality: Chile 1932 and 1973”, 8 Studies in international, Financial, Economic and Technology Law 89 (2007).

FAundez, Julio (2010). "Chilean Constitutionalism Before Allende: Legality Without Courts”, 29 Bulletin of Latin American Research 1, 34 (2010) 35.

Faundez, Julio (2011). Democratización, Desarrollo y Legalidad, Chile 1831-1973, 153, Ediciones Universidad Diego Portales.

Finkel, Jodi S. (2008). Judicial Reform as Political Insurance: Argentina, Peru, and Mexico in The 1990s, University of Notre Dame Press.

Franck, Thomas (1991). The Power of Legitimacy Among Nations, Oxford University Press.

Frente Amplio (2021). Ruta constituyente. Disponible en: https://repodocacto.blob.core.windows.net/public/CCG/D10_FERNANDO_ATRIA_LEMAITRE.pdf

Fundación Facultad de Derecho de la Universidad de Chile (2001) La Jurisdicción Contencioso-Administrativa. Decisiones Legislativas al año 2001.

García, José Francisco (2021). Apuntes constituyentes (I) Transitando de lo genérico a lo específico, El Mercurio Legal 13/4/2021.

García, José Francisco y Verdugo, Sergio (2013). Activismo Judicial en Chile: ¿Hacia el Gobierno de los Jueces. , Ediciones LyD. 
Gargarella, Roberto (2016). "Creación constitucional en sociedades plurales. La “estrategia de la acumulación”, Revista Anales, №10, año 2016, págs. 47-60.

GimÉnEZ S., Isabel M. (2008) "Las leyes de acompañamiento y el problema de las 'leyes ómnibus”, 22 Teoría y Realidad Constitucional 525 (2008).

GinsburG, Tom (2010). "Constitutional Specificity, Unwritten Understandings and Constitutional Agreement”, en András Sajó y Renata Uitz (eds.), Constitutional Topography: Values and Constitutions, Eleven International Publishing, 2010, pág. 71-2.

González-OCAntos, Ezequiel et al. (2021). The Limits of Judicialization: Progress and Backlash in Latin American Politics, Cambridge University Press (en prensa).

GotTfried, Jeffrey et al. (2017). "The Changing Nature of Political Debate Consumption: Social Media, Multitasking, and Knowledge Acquisition”, 34 POLITICAL COMMUNICATION 172 (2017).

GuIDI, Sebastián y NieTo, Juan (2020). Experticia, argumentación y reforma. Los métodos y argumentos del Consejo Consultivo para el Fortalecimiento del Poder Judicial y el Ministerio Público publicado por el Instituto de Investigaciones Jurídicas Ambrosio L. Gioja de la Facultad de Derecho de la Universidad de Buenos Aires, disponible en http://www.derecho.uba.ar/investigacion/pdf/experticia-argumentacion.pdf

Hirschl, Ran (2004) Towards Juristocracy: The Origins and Consequences of the New Constitutionalism Harvard University Press.

Hirschl, Ran (2005). "The Question of Case Selection in Comparative Constitutional Law”, 53 American Journal of Comparative Law 125 (2005).

Hirschl, Ran (2008). "The Judicialization of Mega-Politics and the Rise of Political Courts”, Annual Review of Political Science 2008. 11: 93-118.

Holmes, Stephen (1988). "Precommitment and the Paradox of Democracy", en Jon Elster y Rune Slagstad, Constitutionalism and Democracy, Cambridge University Press.

HuneEus, Jorge (1891). La Constitución ante el Congreso, Tomo II 211-14, Imprenta Cervantes.

Junta de Gobierno (1982). Los Tribunales Contencioso Administrativos, Antecedentes para su Estudio, 305-339 (Armada de Chile).

LAW, David \& Versteeg, Mila (2011). "The Evolution and Ideology of Global Constitutionalism”, 99 CALIF. L. REV. 1163 (2011), 1194-98

LEgRO, Jeffrey W. (1997). "Which norms matter? Revisiting the "failure" of internationalism”, 51 International Organization 31 (1997).

Levinson, Sanford (2011). Constitutional Faith, Princeton University Press (2a ed.).

Levinson, Sanford (2012). Framed: America's 51 Constitutions and the Crisis of Governance, Oxford University Press.

Ming-Sung Kuo (2019). Against instantaneous democracy, 17 INT'L J. CONST. L. 554 (2019). 
MoufFe, Chantal (2016). La paradoja democrática: El peligro del consenso en la política contemporánea, Gedisa, Barcelona.

Pantoja Bauzá, Rolando (1963), "El autor del artículo 87 de la Constitución Política de 1925”, Revista de Derecho Público (1), pp. 15-18.

Pantoja Bauzá, Rolando (2001). "Estudio Preliminar", 13; en Facultad de Derecho Universidad de Chile, La Jurisdicción Contencioso-Administrativa Decisiones Legislativas al año 2001 Documentos, LOM Ediciones.

Pierry A., Pedro (2000), "Tribunales Contenciosos Administrativos", Revista de Derecho del Consejo de Defensa del Estado №2 (diciembre 2000).

Post, Robert y SiEgel, Reva (2013). "La furia contra el fallo 'Roe': constitucionalismo democrático y reacción violenta”, Constitucionalismo democrático. Por una reconciliación entre Constitución y pueblo. Siglo XXI Editores, Buenos Aires.

RESENDE, Ranieri y Ribas Vieira, Jose (2018). "The Agenda-Setting Crisis in the Brazilian Supreme Court", I-CONnect: International Journal of Constitutional Law Blog Disponible en: http://www.iconnectblog.com/2018/04/the-agenda-setting-crisis-in-the-brazilian-supreme-court/ $(15 / 8 / 2018)$.

Serra C., Rosario (2013). "La elección de los miembros del Consejo General del Poder Judicial. Una propuesta de Consejo más integrador e independiente”, 31 Teoría y Realidad Constitucional 277 (2013).

SIERRA Iribarren, Lucas (2020). "Deliberación Constituyente y Judicatura: ¿"Hoja en Blanco"?” 6 Revista de Estudios Judiciales 21.

SIMONCINI, Andrea (2006). "LIstituzione della Corte Costituzionale e la sua Affermazione: Una Lezione dalla Storia”, 11 Giornale dI Storia Costituzionale 295, 295.

Soto, Sebastián (2020). La Hora de la Re-constitución, Ediciones UC.

STONE Sweet, Alec (2000) Governing with Judges: Constitutional Politics in Europe, Oxford University Press.

Strauss, David (2010). The Living Constitution, Oxford University Press.

Sunstein, Cass (2002). Designing Democracy. What Constitutions Do, Oxford University Press, 2011.

Tate, Neal y Vallinder, Torbjorn (1997). The Global Expansion of Judicial Power, NYU Press.

UDI (2021). "Nuestra Visión Constitucional". Disponible en https://repodocacto.blob.core.windows.net/public/CCG/D11_MARCELA_CUBILLOS_SI GALL.pdf

Verbitsky, Horacio (1993). Hacer la Corte. La construcción de un poder absoluto sin justicia ni control, Planeta, Buenos Aires.

Vivanco F., Santiago (1917). De lo Contencioso-Administrativo (Memoria de Prueba de la Facultad de Ciencias Jurídicas y Sociales de la Universidad de Chile). 
VolcanseK, Mary L. (2010). "Bargaining Constitutional Design in Italy: Judicial Review as Political Insurance”, 33 West European Politics 280 (2010).

Weill, Rivka (2021). "Judicial Intervention in Parliamentary Affairs to Prevent a Coup d'état”, Maryland Law Review. Disponible en: https://papers.ssrn.com/sol3/papers.cfm?abstract_id=3880979 


\section{JURISPRUDENCIA CITADA}

\section{Argentina}

Rizzo „Jorge c/ Estado Nacional”(2013): Corte Suprema de la Nación.

\section{Chile}

Socotransco con Fisco, (1964): Corte Suprema de Justicia (Chilean Supreme Court).

\section{United States}

Parents Involved in Community Schools v. Seattle School District No. 1 (2007): United States Supreme Court.

Bush v. Gore (2000): Supreme Court.

Burnet v. Coronado Oil \& Gas Co. (1932): Supreme Court.

\section{United Kingdom}

$R$ (Miller) v The Prime Minister and Cherry v Advocate General for Scotland (2019): Supreme Court of the United Kingdom. 


\section{LEGISLACIÓN CITADA}

\section{Argentina}

Constitución de 1853 (con la reforma de 1860), 25 de septiembre de 1860.

Ley № 24.937 del 10 de diciembre, 1997.

Ley № 24.939, del 2 de enero, 1998.

Ley № 26.885, del 24 de mayo, 2013.

Ley № 24.430, del 3 de enero 1995.

Constitución Nacional de Argentina.

\section{Australia}

Commonwealth of Australian Constitution Act, 1 de enero 1901.

\section{Chile}

Código Orgánico de Tribunales, 9 de julio de 1943.

Constitución Política de la República de Chile, 18 de septiembre de 1925.

Constitución Política de la República, versión al 28 de abril de 2021.

Ley de Organización y Atribuciones de los Tribunales de Chile, 15 de octubre, 1875.

Ley Boletín Bill № 14192-07, ingresado el 21 de abril, 2021.

\section{Estados Unidos}

Constitución de los Estados Unidos, 4 de marzo, 1789.

\section{Italia}

Luogotenenziale Decreto legislativo № 98 del 16 de marzo, 1946. 